\title{
A three-dimensional finite element model of round window membrane vibration before and after stapedotomy surgery
}

\author{
Monika Kwacz • Piotr Marek • Paweł Borkowski • \\ Maciej Mrówka
}

Received: 2 May 2012 / Accepted: 15 February 2013 / Published online: 5 March 2013

(C) The Author(s) 2013. This article is published with open access at Springerlink.com

\begin{abstract}
Piston stapes prostheses are implanted in patients with refractory conductive or mixed hearing loss due to stapes otosclerosis to stimulate the perilymph with varying degrees of success. The overclosure effect described by the majority of researchers affects mainly low and medium frequencies, and a large number of patients report a lack of satisfactory results for frequencies above $2 \mathrm{kHz}$. The mechanics of perilymph stimulation with the piston have not been studied in a systematic manner. The objective of this study was to assess the influence of stapedotomy surgery on round window membrane vibration and to estimate the postoperative outcomes using the finite element (FE) method. The study hypothesis is that the three-dimensional FE model developed of the human inner ear, which simulates the round window (RW) membrane vibration, can be used to assess the influence of stapedotomy on auditory outcomes achieved after the surgical procedure. An additional objective of the study was to enable the simulation of RW membrane vibration after stapedotomy using a new type of stapes prosthesis currently under investigation at Warsaw University of Technology. A three-dimensional finite element (FE) model of the human inner ear was developed and validated using experimental data. The model was then used to simulate the round
\end{abstract}

M. Kwacz ( $\varangle)$

Faculty of Mechatronics, Institute of Micromechanics

and Photonics, Warsaw University of Technology,

ul. św. A. Boboli 8, 02-525 Warsaw, Poland

e-mail: m.kwacz@mchtr.pw.edu.pl

P. Marek · P. Borkowski

Faculty of Power and Aeronautical Engineering, Institute of Aeronautics and Applied Mechanics, Warsaw University

of Technology, ul. Nowowiejska 24, 00-665 Warsaw, Poland

M. Mrówka

Institute of Physiology and Pathology of Hearing, ul. Mokra 17,

05-830 Nadarzyn, Poland window membrane vibration before and after stapedotomy surgery. Functional alterations of the RW membrane vibration were derived from the model and compared with the results of experimental measurements from temporal bones of a human cadaver. Piston stapes prosthesis implantation causes an approximately fivefold $(14 \mathrm{~dB})$ lower amplitude of the RW membrane vibrations compared with normal anatomical conditions. A satisfactory agreement between the FE model and the experimental data was found. The new prosthesis caused an increase of 20-30 dB in the RW displacement amplitude compared with the $0.4-\mathrm{mm}$ piston prosthesis. In all frequencies, the FE model predicted a RW displacement curve that was above the experimental curves for the normal ear. The stapedotomy can be well simulated by the FE model to predict the auditory outcomes achieved following this otosurgery procedure. The 3D FE model developed in this study may be used to optimize the geometry of a new type of stapes prosthesis in order to achieve a similar sound transmission through the inner ear as for a normal middle ear. This should provide better auditory outcomes for patients with stapedial otosclerosis.

Keywords Finite element model · Inner ear · Stapedotomy · Piston stapes prosthesis $\cdot$ Round window vibration

\section{Abbreviations}

AL Annular ligament

A_in

A_rw

Input displacement amplitude

Displacement amplitude of the round window membrane

A_rw_postE0.4 Displacement amplitude of the round window membrane measured from the 
temporal bone following the stapedotomy surgery with the $0.4-\mathrm{mm}$ piston prostesis

A_rw_postM0.4 Displacement amplitude of the round window membrane derived from the FE post-stapedotomy model with the 0.4$\mathrm{mm}$ piston prosthesis

A_rw_postM0.6 Displacement amplitude of the round window membrane derived from the FE post-stapedotomy model with the 0.6$\mathrm{mm}$ piston prosthesis

A_rw_preE Displacement amplitude of the round window membrane measured from the temporal bone in the normal physiological state (pre-stapedotomy)

A_rw_preM Displacement amplitude of the round window membrane derived from the FE pre-stapedotomy model

$\Delta$ Arw $\quad$ Change in the round window membrane displacement amplitude between the pre-stapedotomy and the post-stapedotomy states

BM

f

RW

SF

SPL

ST

SV

Basilar membrane

Frequency

Round window

Stapes footplate

Sound pressure level

Scala tympani

Scala vestibuli

\section{Introduction}

Stapedotomy surgery, first performed by Shea in 1956 (Shea 1958; Shea et al. 1962), is a commonly recognized, relatively safe and efficient surgical technique for certain types of auditory ossicle immobility, especially stiffening of the interface between the stapes footplate and the oval window, particularly in the course of otosclerosis (Rizer and Lippy 1993; Dubreuil et al. 1994; Häusler 2004; Somers et al. 2006; Vincent et al. 2006; Møller 2007). In stapedial otosclerosis, the stapes is immobilized by bone growth in the oval window niche. Fixation of the stapes footplate decreases its ability to vibrate, thereby significantly modifying the function of the normal ossicular chain, and always leads to conductive hearing loss (Dubreuil et al. 1994; Häusler 2004; Møller 2007). Stapedotomy surgery involves removing the superstructure of the otosclerotic stapes, drilling a small hole in the center of the immobilized stapes footplate, placing the piston of the stapes prosthesis $(0.4-0.6 \mathrm{~mm}$ in diameter $)$ into the hole, and tightening a wire or ribbon on the long process of the incus. The longitudinal vibration of the piston mimics the vibration of the normal stapes footplate, generates a pressure wave into the cochlea, and activates the sensory hair cells. The auditory

outcomes obtained following the surgery should generally be perceived as good, but the good overclosure effect described by the majority of researchers mainly affects low $(0.5 \mathrm{kHz})$ and medium frequencies ( 1 and $2 \mathrm{kHz}$ ) and a large number of patients report a lack of satisfactory results for frequencies above 2 kHz (Rizer and Lippy 1993; Häusler 2004; Somers et al. 2006; Vincent et al. 2006).

It has been shown (Wysocki et al. 2011) that the stapes piston prosthesis leads to an approximately $14 \mathrm{~dB}$ lower stimulation of perilymph vibration at RW compared to the physiological situation, in particular at frequencies exceeding $2 \mathrm{kHz}$. It has also been verified experimentally that the vibration amplitudes of the stapes piston prosthesis and the normal stapes are of the same order magnitude, while maintaining the same frequencies and sound pressure levels as the sounds supplied to the external auditory canal. This $14 \mathrm{~dB}$ lower stimulation of the perilymph may provide an explanation for the lack of the expected auditory outcome after stapedotomy surgery, especially for frequencies above $2 \mathrm{kHz}$.

Numerous clinical, experimental, and modeling studies have dealt with diagnosis of ear conditions, the design of implantable prostheses and hearing devices, and evaluation of devices or surgical treatment. In the modeling studies, several different methods are used to model hearing biomechanics.

Firstly, the analogy modeling method, represented by circuit or lumped parameter models based on acoustic-electrical analogues of the ear, has been developed and applied to predict the normal, pathological, and reconstructed behavior of both the middle (Møller 1961; Zwisłocki 1962; Shaw and Stinson 1981; Lynch et al. 1982; Kringlebotn 1988; Goode et al. 1994; Rosowski and Merchant 1995; Rosowski 1996; Feng and Gan 2004) and inner ear (Lyon and Mead 1988; Suesserman and Spelman 1993; Vanpoucke et al. 2004; Mistrík et al. 2009). Although these models are able to replicate experimental data, their parameters are not closely related to anatomical or physiological properties. Because of this, the analogy modeling method cannot be used to optimize the geometry of new types of middle ear prostheses.

Secondly, the oscillation of the cochlear partitions has been studied by analytical methods using two-dimensional and simplified three-dimensional models to investigate passive cochlear macro-mechanics, especially the vibration of the basilar membrane (Steele and Taber 1979; de Boer 1982; Kolston and Ashmore 1996; Parthasarati et al. 2000; Yoon et al. 2009). Mathematically, the macro-mechanical system of the cochlea can be described by fluid-mechanical equations coupled with equations describing the elastic properties of the BM, the bony walls of the SV and the ST, the RW membrane, and the oval window covered with elastic membrane. The mathematical problem of solving this system of partial differential equations on a three-dimensional domain is very difficult and requires application of advanced computational 
methods. In addition, the passive cochlear macro-mechanics cannot explain the extreme sensitivity and frequency selectivity of the basilar membrane. Since the discovery of outer hair cells (OHCs) electromotility (Brownell et al. 1985), cochlear modeling has been focusing on exploring active process and nonlinear behavior in the BM responses measured in the live cochlea. A number of active cochlear models have introduced OHC motility into cochlear macro- and micromechanics (Kolston et al. 1989; Hubbard 1993; Neely 1993; Geisler 1993; Geisler and Sang 1995; Fukazawa 2002; Lim and Steele 2002; Shatz 2005; Yoon et al. 2009, 2011). The nonlinear models were either solved in the time domain or in the frequency domain using iterative or perturbation techniques. Our purpose, however, is not to study the active behavior of the cochlea, but to predict the auditory outcomes achieved following stapedotomy surgery with various types of stapes prostheses.

Finally, finite element (FE) methods have been applied to study the function of the normal or reconstructed human middle (Wada et al. 1992; Funnell 1996; Ferris and Prendergast 2000; Daniel et al. 2001; Kelly and Prendergast 2001; Gan et al. 2002, 2004, 2007, 2009, 2010; Gil-Carcedo et al. 2002; Koike et al. 2002; Sun et al. 2002; Kelly et al. 2003; Böhnke and Arnold 2007; Zhao et al. 2009; Zhang and Gan 2011) and inner ear (Böhnke and Arnold 1999; Hanekom 2001, 2005; Kiefer et al. 2006; Ramamoorthy et al. 2007). The FE method is a numerical technique commonly used to model mechanical behavior of complex biological systems. This technique is especially useful for simulating the behavior of structures in conditions that cannot be achieved experimentally and is suitable for modeling the complex geometry and anisotropic material properties of biological systems. The first FE model of the cat tympanic membrane was reported by Funnell and Laszlo (1978). Since then, FE modeling of middle and inner ear dynamic has become a fast growing research area in the study of auditory mechanics. The FE models were used to simulate the detailed vibration shapes, stress distributions, and dynamic behaviors at any location in the hearing organ. In order to create a useful model that can simulate the functional behavior of the inner ear, most of the authors simplify the complex cochlear anatomy, especially often its coiled shape, and approximate the dimensions, boundary conditions, and material properties of cochlear tissues. Recently, there have been two major reasons for developing FE models - one is to simulate the acoustic-mechanical transmission from the external auditory canal to the cochlea with a focus on the middle ear's transfer function (Koike et al. 2002; Gan et al. 2004, 2006, 2007, 2009; Gan and Wang 2007; Zhao et al. 2009). The other is to simulate the pressure wave traveling along the basilar membrane from the oval window to the apex in the cochlea with a focus on cochlear mechanics (Gan et al. 2007; Gan and Wang 2007; Böhnke and Arnold 2007).
Despite a range of modeling studies, there is still limited information on sound transmission through the inner ear after stapedotomy surgery, mainly due to an insufficient number of experimental and theoretical studies. The aim of this study is to assess the influence of various types of stapes prostheses on the round window membrane vibration and estimate the postoperative outcomes using the finite element (FE) method. By comparing the response of the normal ear to that of the ear with prosthesis inserted, it is expected that advances can be made in improving the design of a new stapes prosthesis.

\subsection{Objective of the study}

The study hypothesis is that the three-dimensional FE model developed for the human inner ear, which simulates the round window (RW) membrane vibration determining the intensity of energy transmission from the outer ear to the inner ear compartments, can be used to assess the influence of stapedotomy on auditory outcomes achieved after the surgical procedure. Differences in the magnitudes of vibration amplitude were expected to occur, particularly for different sound frequencies. This could confirm clinical observations indicating variable auditory outcomes of stapedotomy for individual frequencies.

An additional objective of the study was to enable the simulation of RW membrane vibration parameters after stapedotomy using a new type of stapes prosthesis currently under investigation at Warsaw University of Technology. The parameters calculated may be used to optimize the geometry of the prosthesis in order to achieve a similar intensity of sound transmission as in the case of the normal middle ear. This should provide better auditory outcomes for patients with stapedial otosclerosis.

\section{Materials and methods}

The modeling studies were conducted using a 3D finite element model of the uncoiled cochlea and consisted of simulation of the RW membrane vibration amplitude in the frequency range $0.4-10 \mathrm{kHz}$ in both the pre-stapedotomy and post-stapedotomy states. In the post-stapedotomy state, the differences in the RW membrane displacement amplitudes were studied for two piston prostheses of different diameters $(0.4$ and $0.6 \mathrm{~mm})$. The vibrations of the RW membrane obtained from the FE model were subsequently compared with the results of experimental measurements in human temporal bones using the scanning laser Doppler vibrometer (SLDV PSV 400 system, Polytec GmbH, Waldbronn, Germany). 
In addition, by using the model developed, round window membrane vibrations were predicted after implantation of a new type of stapes prosthesis.

\subsection{D finite element model of the inner ear/geometry and mesh of the inner ear structures}

\subsubsection{The pre-stapedotomy model}

The three-dimensional FE model of the uncoiled cochlea consists of two straight fluid channels representing the scala vestibuli (SV) and scala tympani (ST), separated by the basilar membrane (BM). The third channel (scala media) was included in the SV. The Reissner's membrane and the micromechanical structures of the organ of Corti were not considered in the model. The stapes footplate (SF) was attached to the SV in the oval window by an annular ligament (AL) and the ST was connected to the middle ear cavity at the round window niche by the RW membrane. The SV and ST were filled with an viscous perilymph fluid. At the apex region, these two channels were connected to each other through the helicotrema.

The geometry of the inner ear structures was adopted according to dimensions published in the literature (Gan et al. 2007), similar to the real coiled geometry of the cochlea. Our FE model was constructed based on the information given by Gan's group, but these two models differ from each other. The main differences are the geometry of the stapes footplate, the annular ligament, the RW membrane, the variable height of both SV and ST, the finite element mesh and number of finite elements for the individual structures, the material properties of the stapes footplate and the annular ligament, except density of the AL. The geometry was then meshed in ANSYS 13.0 (Ansys, Inc., Canonsburg, PA). Figure 1 shows the structure of the simplified cochlear model with detailed dimensions and FE meshes of the anatomical structures.

The fluid-filled SV and ST channels were assumed to change linearly in height from $2.0 \mathrm{~mm}$ at the base to 1.0 $\mathrm{mm}$ at the apex and from $1.5 \mathrm{~mm}$ at the base to $0.7 \mathrm{~mm}$ at the apex, respectively. The length of both the SV and ST was assumed to be $33.8 \mathrm{~mm}$ and the width was assumed to change linearly from $4.3 \mathrm{~mm}$ at the base to $1.7 \mathrm{~mm}$ at the apex. The helicotrema opening at the apex was modeled as a rectangular fluid passageway with dimensions of $1.7 \times 1.8 \mathrm{~mm}$. The $\mathrm{SV}$ and the ST channels with the helicotrema were filled with a viscous fluid and meshed by 116020 eight-node hexahedral fluid elements (Fluid80 in ANSYS). The Fluid80 elements at a boundary are not directly attached to the structural Solid 45 elements (of the BM, the RW membrane, the SF, and the AL) but have separate, coincident nodes that are coupled only in the direction normal to the interface.

The BM dimensions were assumed to change linearly in width from $0.1 \mathrm{~mm}$ at the base to $0.5 \mathrm{~mm}$ at the apex and in thickness from $7.5 \mu \mathrm{m}$ at the base to $2.5 \mu \mathrm{m}$ at the apex. The length of the BM was assumed as $31.9 \mathrm{~mm}$. The BM was meshed by 2400 eight-node 3D hexahedral solid elements (Solid45 in ANSYS). The boundary conditions for the BM were defined as fully clamped (all displacements and rotations zero) at the spiral lamina and simply supported (all displacement zero) at the spiral ligament. This is motivated by Iurato's anatomical studies (Iurato 1962), in which the main supporting bundles of the spiral lamina continue directly into the fibers of the BM, suggesting a clamped condition. On the other side of the BM, the fibers continue directly into the spiral ligament but suddenly become thinner prior to joining the spiral ligament, suggesting a simply supported boundary condition.

The SF was assumed to be an ellipse with a long axis of $2.24 \mathrm{~mm}$ and a short axis of $1.4 \mathrm{~mm}$. The AL was assumed to be an elliptical ring with a width changing from $0.1 \mathrm{~mm}$ in the long axis to $0.04 \mathrm{~mm}$ in the short axis. The thickness of both the AL and the SF was assumed to be $0.2 \mathrm{~mm}$. The RW membrane was assumed as a circle with a diameter of $1.2 \mathrm{~mm}$ and a thickness of $0.05 \mathrm{~mm}$. All nodes along the outer perimeters of both the $\mathrm{AL}$ and the RW membrane were fixed. The nodes along the inner perimeter of the AL were connected with the nodes along the outer perimeter of the $\mathrm{SF}$. The $\mathrm{AL}$, the SF, and the RW membrane were meshed by 360,300 , and 300 eight-node 3D hexahedral solid elements (Solid45), respectively. The FE mesh has been adopted taking into account a trade-off between computational time and accuracy. To establish that the mesh was fine enough, we have performed a series of simulations with different mesh density until the simulation results no change by more than $5 \%$. The accuracy of simulation results was defined as the correlation between the model-derived and experimental magnitudes of the RW membrane displacements in the prestapedotomy state. Correlation analysis (when the AL, the SF, and the RW membrane were meshed by 360,300 , and 300 elements, respectively) between the model and experimental results for frequencies $<8 \mathrm{kHz}$ was significant except the correlation at $0.63 \mathrm{kHz}$ (Pearson correlation coefficient $r=0.91, p<0.05$ ). Figure 5 shows the experimental and model-derived curves obtained for the accepted FE mesh. Differences between the model results and experiments at 8 $\mathrm{kHz}$ and $10 \mathrm{kHz}$ were described in the chapter Discussion.

\subsubsection{The post-stapedotomy model}

To assess the effect of stapedotomy on sound transmission into the inner ear, the pre-stapedotomy model was modified as follows: the SF was immobilized by complete fixation of the $\mathrm{AL}$ nodes, a hole with a diameter of $0.4 \mathrm{~mm}$ was made in the center of the SF, and the piston of the stapes prosthesis with the same diameter was placed into the hole. The piston of the stapes prosthesis was assumed as a cylinder 

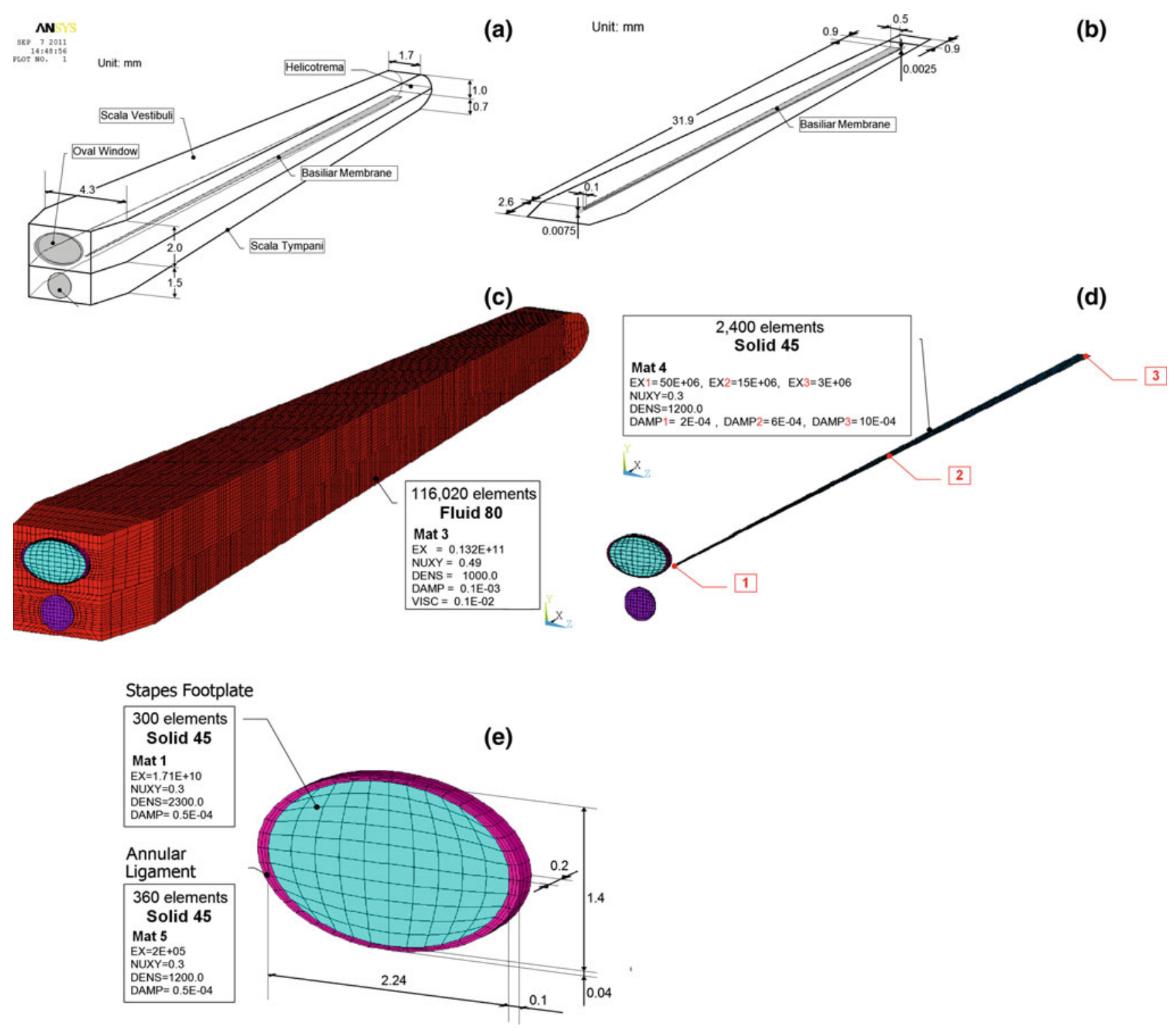

Fig. 1 The structure of the simplified cochlear model with detailed dimensions and FE meshes of the anatomical structures in the prestapedotomy FE state. a 3D schematic view of the uncoiled cochlea showing the overall dimensions of the scala vestibule (SV) and the scala tympani (ST), b 3D view of the basilar membrane (BM) and the supported structures of the BM with detailed dimensions of the BM, c $3 \mathrm{D}$ view of the uncoiled cochlea showing the FE mesh of both the SV

with a diameter of $0.4 \mathrm{~mm}$ and a length of $2.2 \mathrm{~mm}$ (Fig. 2). The piston was meshed by 192 eight-node 3D hexahedral solid elements (Solid45 in ANSYS). The geometry, boundary conditions, and FE meshes of the other elements of the post-stapedotomy model were left the same as in the prestapedotomy model.

\subsection{Material properties of the inner ear structures}

The material properties of the inner ear structures were initially assumed according to the properties published in the and the ST with the mechanical properties assumed in the FE model, d $3 \mathrm{D}$ view of the $\mathrm{BM}$ with the mechanical properties assumed in the $\mathrm{FE}$ model, 1 -at the base, 2-in the middle, 3-at the apex, e 3D view of the stapes footplate (SF, blue), the annular ligament (AL, pink), and the round window membrane ( $\mathrm{RW}$, violet) showing the detailed dimensions, the FE meshes, and the mechanical properties of these three structures

literature. These parameters were then checked and some of them modified in the validation process. The mechanical properties of the inner ear structures used in the inner ear model, including the density, Young's modulus, and Raleigh damping parameters $\alpha$ and $\beta$ of the SF, the piston of the stapes prosthesis, the AL, the RW membrane, and the BM, are listed in Table 1.

All solid materials, except the BM, in both the prestapedotomy and post-stapedotomy models were assumed as isotropic materials with the Poisson's ratio of 0.3 and the damping coefficient $\beta$ of $0.5 \mathrm{E}-04 \mathrm{~s}$. The Young's moduli of 
(a)

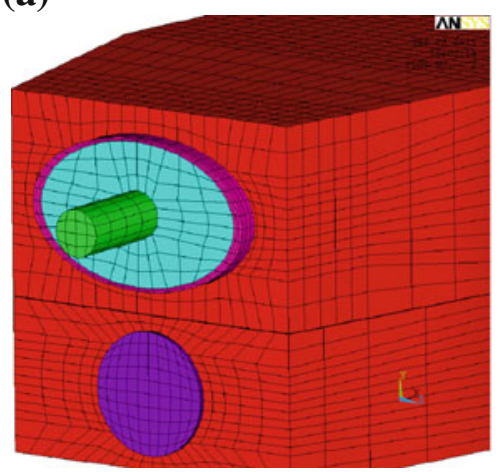

Fig. 2 The structure of the simplified cochlear model in the poststapedotomy state. The geometry, boundary conditions, and FE meshes of the other elements of the post-stapedotomy model were left the same as in the pre-stapedotomy model. a 3D schematic view showing the shape and the location of the piston stapes prosthesis (green) in the

\section{(b)}

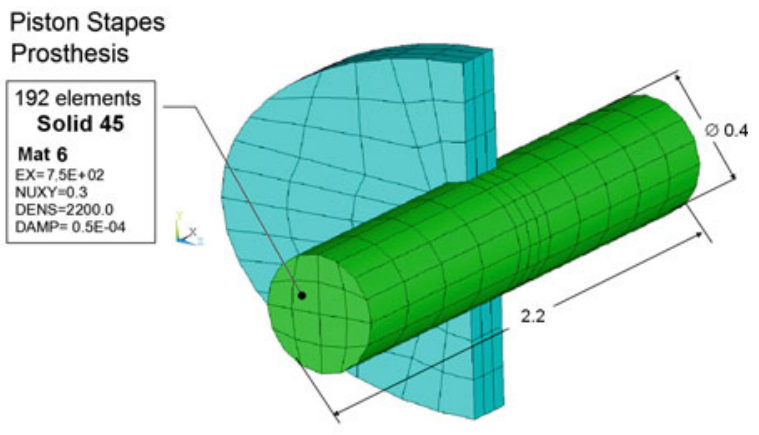

stapes footplate (blue), b 3D view of the stapes footplate and the piston of the prosthesis showing the dimensions, the FE mesh, and the mechanical properties of the piston and the modified FE mesh of the stapes footplate
Table 1 Mechanical properties of the ear structures used in the FE inner ear model

\begin{tabular}{|c|c|c|}
\hline Structure & Data used in the FE model & Source \\
\hline \multicolumn{3}{|l|}{ Stapes footplate (SF) } \\
\hline Density $\left(\mathrm{kg} / \mathrm{m}^{3}\right)$ & $2.30 \mathrm{E} 3$ & The FE model \\
\hline Young's modulus (N/m²) & $1.71 \mathrm{E} 10$ & $\begin{array}{l}\text { The FE model (determined by the FE } \\
\text { model validation process) }\end{array}$ \\
\hline Damping & $\alpha=0 \mathrm{~s}^{-1}, \beta=0.00005 \mathrm{~s}$ & $\begin{array}{l}\text { The FE model (determined by the FE } \\
\text { model validation process) }\end{array}$ \\
\hline \multicolumn{3}{|l|}{ Annular ligament $(A L)$} \\
\hline Density $\left(\mathrm{kg} / \mathrm{m}^{3}\right)$ & $1.20 \mathrm{E} 3$ & Gan et al. 2007 \\
\hline Young's modulus $\left(\mathrm{N} / \mathrm{m}^{2}\right)$ & $2.00 \mathrm{E} 5$ & Gan 2006 \\
\hline Damping & $\alpha=0 \mathrm{~s}^{-1}, \beta=0.00005 \mathrm{~s}$ & $\begin{array}{l}\text { The FE model (determined by the FE } \\
\text { model validation process) }\end{array}$ \\
\hline \multicolumn{3}{|c|}{ Round window membrane ( $R W)$} \\
\hline Density $\left(\mathrm{kg} / \mathrm{m}^{3}\right)$ & $1.20 \mathrm{E} 3$ & Gan et al. 2007 \\
\hline Young's modulus $\left(\mathrm{N} / \mathrm{m}^{2}\right)$ & $3.50 \mathrm{E} 5$ & Gan et al. 2007 \\
\hline Damping & $\alpha=0 \mathrm{~s}^{-1}, \beta=0.00005 \mathrm{~s}$ & Gan et al. 2007 \\
\hline \multicolumn{3}{|l|}{ Basilar membrane (BM) } \\
\hline Density $\left(\mathrm{kg} / \mathrm{m}^{3}\right)$ & $1.20 \mathrm{E} 3$ & Gan et al. 2007 \\
\hline \multicolumn{3}{|l|}{ Young's modulus (N/m²) } \\
\hline At the base & $5.00 \mathrm{E} 7$ & Gan et al. 2007 \\
\hline In the middle & $1.50 \mathrm{E} 7$ & Gan et al. 2007 \\
\hline At the apex & $3.00 \mathrm{E} 6$ & Gan et al. 2007 \\
\hline \multicolumn{3}{|l|}{ Damping } \\
\hline At the base & $\alpha=0 \mathrm{~s}^{-1}, \beta=0.0002 \mathrm{~s}$ & Gan et al. 2007 \\
\hline In the middle & $\alpha=0 \mathrm{~s}^{-1}, \beta=0.0006 \mathrm{~s}$ & Gan et al. 2007 \\
\hline At the apex & $\alpha=0 \mathrm{~s}^{-1}, \beta=0.001 \mathrm{~s}$ & Gan et al. 2007 \\
\hline \multicolumn{3}{|l|}{ Perilymph fluid } \\
\hline Density $\left(\mathrm{kg} / \mathrm{m}^{3}\right)$ & $1.00 \mathrm{E} 3$ & Gan et al. 2007 \\
\hline Bulk modulus $\left(\mathrm{N} / \mathrm{m}^{2}\right)$ & $2.2 \mathrm{E} 9$ & Gan et al. 2007 \\
\hline Damping & $\alpha=0.001 \mathrm{~s}^{-1}, \beta=0.0001 \mathrm{~s}$ & Gan et al. 2007 \\
\hline
\end{tabular}


the SF, the piston of the stapes prosthesis, the AL, and the RW membrane were assumed as $1.71 \mathrm{E}+04,750,0.2$, and $0.35 \mathrm{MPa}$, respectively. The density of the structures mentioned above was assumed as 2,300, 2,200, 1,200, and 1,200 $\mathrm{kg} / \mathrm{m}^{3}$, respectively.

The BM was treated as a material with a Poisson's ratio of 0.3 and a density of $1,200 \mathrm{~kg} / \mathrm{m}^{3}$. We assumed the Poisson's ratio of 0.3 after Gan et al. (2007; p. 2182). The effect of the Poisson's ratio on the BM membrane deflection was checked by Liu and White (2008). In Fig. 4, they showed that the choice of this parameter $(0.2$ or 0.4$)$ does not have a major impact on vertical displacement of the BM. It is well known that the BM stiffness varies along its length (Emadi et al. 2004; Liu and White 2008). According to the data used in a 3D cochlea model by Gan et al. (2007, 2009), the Young's modulus of the BM was assumed to change from $50 \mathrm{MPa}$ at the base to $3 \mathrm{MPa}$ at the apex. Having determined the Young's modulus value of the BM, the damping in the FE model was then adjusted so that the derived RW responses matched with both our experimental results and data from the literature (Asai et al. 1999; Stenfelt et al. 2004a,b). The damping was adjusted by varying the material damping factor $(\beta)$ of the $\mathrm{BM}$. While adjusting the BM damping, the $\mathrm{BM}$ responses were also checked. The damping coefficient $\beta$ of the BM was finally assumed to change from $0.2 \mathrm{E}-03 \mathrm{~s}$ at the base to $0.1 \mathrm{E}-02 \mathrm{~s}$ at the apex.

The perilymph fluid filling the SV and ST in the cochlea was assumed as a viscous fluid with a density of $1,000 \mathrm{~kg} / \mathrm{m}^{3}$. The viscosity of the fluid was assumed to be $0.001 \mathrm{Ns} / \mathrm{m}^{2}$.

\subsection{Finite element analysis}

Structural and fluid FE analyses were performed in ANSYS 13.0 (ANSYS, Inc., Canonsburg, PA) to determine the displacement amplitudes of the RW membrane at different frequencies, from both the pre-stapedotomy and the poststapedotomy model.

The motion of perilymph fluid in the cochlea is assumed to be described by the continuity equation for small-compressible flow:

$P=-k \nabla \cdot \boldsymbol{u}$

where $P$ is pressure, $\boldsymbol{u}$ is the displacement vector, $k$ is the bulk modulus of fluid, and $k=c^{2} \rho$. In this study, the coefficient $k$ was assumed to be $2.20 \mathrm{GPa}$.

The harmonic analysis was conducted within the auditory frequency range of $0.4-10.0 \mathrm{kHz}$. The displacement excitation was applied at the nodes of either the SF or the piston prosthesis along the direction perpendicular to the footplate. The magnitudes of the displacement amplitudes were assumed to be exactly the same as the magnitudes measured for the human temporal bones in our experiment using a scanning laser Doppler vibrometer.
In this study, the investigations were conducted using a two-step scheme.

Firstly, the FE analysis from the pre-stapedotomy model was employed to determine the displacement-frequency curve of the RW membrane and to adjust and validate the model. In the model validation process, the harmonic displacement excitation was applied to the surface of the SF, the vibration response of the RW membrane was calculated, and the values of the model parameters were estimated to achieve satisfactory agreements between the model and experimental data.

Secondly, the FE analysis of the post-stapedotomy model was employed to investigate the effect of piston prosthesis insertion on the RW membrane vibration using the validated FE model.

\subsection{Measurement in human temporal bones}

Four isolated human temporal bones, three males and one female, selected at the Forensic Medicine Institute of the Warsaw Medical University were included in this study. The donors' ages were 18, 27, 29, and 37 years.

The methods for temporal bone preparation, the experimental stapedotomy procedure, acoustic and optical pathway structure and calibration, and round window vibration patterns before and after stapedotomy have already been detailed elsewhere (Wysocki et al. 2011).

In brief, human cadaver temporal bones were prepared by shortening the bony ear canal to approximately $1 \mathrm{~cm}$, placing a polyurethane foam ear tip (ER3-14A, Etymotic Research, Elk Grove Village, IL) in it, performing a maximally wide posterior tympanotomy, and a wide approach in the RW niche through the jugular fossa. Sound stimulation was introduced to a sealed ear canal from an insert earphone (ER-2, Etymotic Research) via a flexible sound delivery tube with adapter (ER1-21, Etymotic Research). The ear canal sound pressure level (SPL) was recorded with a calibrated probe tube microphone (ER-7C Etymotic Research) with the tip of the flexible probe tube (ER7-14C, Etymotic Research) positioned approximately $2 \mathrm{~mm}$ distant from the tympanic membrane. Based on the SPL value measured by the microphone, we corrected the amplification of the input acoustic signal supplied to the loudspeaker to maintain a constant SPL value of $90 \mathrm{~dB}$ for each of the measurement frequencies in a $0.4-10$ $\mathrm{kHz}$ frequency range.

At the first stage of measurement (the pre-stapedotomy state), the vibration amplitudes of both the RW and the stapes were recorded in normal anatomical conditions. Then, in the same specimen, the stapes footplate was immobilized in the OW niche with glass ionomer cement and the experimental stapedotomy procedure was performed with a standard Teflon piston stapes prosthesis (DEMED ${ }^{\circledR}$, Mikołów, Poland). Two Teflon piston prostheses of different diameters 
(0.4 and $0.6 \mathrm{~mm}$ ) were used successively. Immediately after the piston with a diameter of $0.4 \mathrm{~mm}$ was inserted, another series of vibration amplitudes of both the RW and the prosthesis was recorded (post-stapedotomy state 1). Afterward, in the same specimen, the hole was enlarged, the other prosthesis with a piston diameter of $0.6 \mathrm{~mm}$ was placed into the hole, and the last series of the vibration amplitudes of both the RW and the prosthesis was recorded (post-stapedotomy state 2).

The stapes, stapes prosthesis, and RW displacements were measured with two scanning laser Doppler vibrometers (PSV400, Polytec GmbH, Waldbronn, Germany). One laser was directed through the posterior tympanotomy at the stapes for the pre-stapedotomy state or at the piston for the poststapedotomy state. The deviation of this laser beam varied $25^{\circ}-40^{\circ}$ with respect to the direction of the stapes movement (i.e., the direction perpendicular to the plane of the stapes footplate). The other laser was directed through the jugular fossa at the RW membrane for both the pre-stapedotomy and post-stapedotomy state. The deviation of the laser beam with respect to the direction of RW membrane movement varied $15^{\circ}-35^{\circ}$. The deviation angles of the laser beams were used as a cosine correction factor to obtain the real displacement amplitudes of the measured structures.

The vibrometer controller was programmed to generate a succession of acoustic input signals with a center frequency of successive one-third octave bands: $0.40,0.50,0.63,0.80$, $1.00,1.25,1.60,2.00,2.50,3.15,4.00,5.00,6.30,8.00$, and $10.0 \mathrm{kHz}$. For each measurement frequency, the sound pressure level was maintained at the same value of $90 \mathrm{~dB}$.

The displacement amplitudes of the stapes head and piston prosthesis obtained from the measurements were then used in our FE model as amplitudes of the harmonic displacement excitations for the pre-stapedotomy and post-stapedotomy model, respectively. The experimental displacement-frequency curve of the RW membrane for the pre-stapedotomy state was then used to validate the FE model and the curves for the post-stapedotomy state as control data.

\section{Results}

\subsection{Displacement excitation A_in}

The vibration responses of the SF and piston stapes prosthesis with air conduction (AC) stimulation were measured in four temporal bone specimens using a scanning LDV system. Figure 3 presents the results (the mean values determined for 73 scan points on the stapes head and 38 scan points on the piston prosthesis) from all four specimens. In this study, we analyzed the experimental and modelderived amplitude frequency profiles for Specimen 1. The pre- and post-stapedotomy profiles for all measurement points from Specimen 1 were presented in Kwacz et al. (2012, Figure 2).

Based on the experimental amplitude frequency profiles, the input displacement amplitude A_in at each measurement frequency was determined as the average value of the displacement amplitudes measured on the surface of the stapes head (pre-stapedotomy state) and piston stapes prosthesis (post-stapedotomy state). The pre-stapedoptomy and poststapedotomy input displacement amplitudes for specimen 1 are shown in Fig. 4 and in Table 2. These displacement amplitudes A_in were assumed as the amplitudes of the harmonic displacement excitations in the pre-stapedotomy and poststapedotomy FE model.

\subsection{Validation of the FE model}

The FE model of a normal cochlea (pre-stapedotmy model) was first validated by comparing the displacement-frequency curves of the RW membrane derived from the model with the experimental data obtained from human temporal bones.

In the validation process, the initial displacements were assumed as harmonic displacements of A_in pre-stapedotomy amplitudes (Table 2) and applied to all nodes of the normal $\mathrm{SF}$ in the direction perpendicular to the footplate. Then, the magnitudes of the RW membrane displacements for the central point on the RW membrane were calculated from the FE model for each measurement frequency.

The experimental displacement-frequency curves of the RW membrane were reported in our previous paper (Wysocki et al. 2011). It should be noted that only four points at the center of the RW membrane were considered for validation. For these four points, the average value of RW membrane displacement was calculated and adopted for comparison with the model-derived value for each measurement frequency.

Figure 5 shows the model-derived frequency response curve of the RW membrane displacement in comparison with the corresponding curves obtained from four temporal bone specimens in the pre-stapedotomy state when $90 \mathrm{~dB}$ SPL pure tones were applied in the external ear canal.

As can be seen in Fig. 5, the FE model-predicted RW displacement curve falls within the range of the four temporal bone experimental curves across the frequency range of 0.5-7 kHz. However, there are some discrepancies between the model and experimental results. The displacement magnitudes from modeling at high frequencies $(f>7 \mathrm{kHz})$ lie below the experimental curves. The model did not show either the pronounced peak at $1.25 \mathrm{kHz}$ or the minimum at $0.63 \mathrm{kHz}$ that were seen experimentally in all specimens. At frequencies of $1-2 \mathrm{kHz}$, the $\mathrm{FE}$ model curve is slightly lower than the mean experimental curve. However, the trend of the FM model-predicted RW displacement curve is similar to the mean experimental curve. 

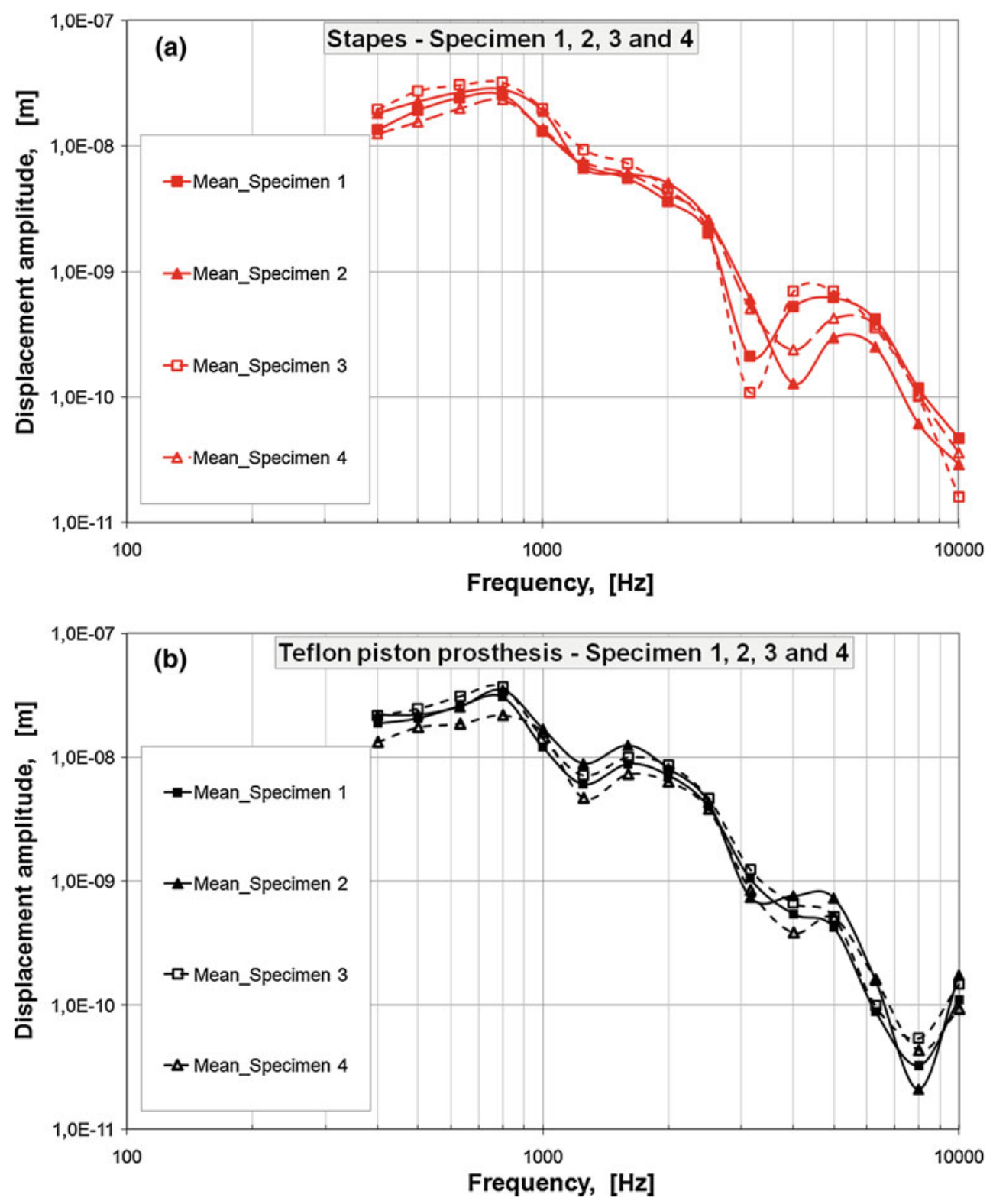

Fig. 3 Displacement amplitudes of a stapes head and $\mathbf{b}$ stapes piston prosthesis for four temporal bones. The mean values were determined for 73 scan points on the stapes head and 38 scan points on the piston

Figure 6 shows the model-derived BM responses obtained for different values of the BM damping coefficient $\beta$ (0.1*DAMP, DAMP, $10^{*}$ DAMP, where DAMP changes linearly from $0.2 \mathrm{E}-03 \mathrm{~s}$ at the base to $0.1 \mathrm{E}-02 \mathrm{~s}$ at the apex). As can be seen, the damping coefficient affects decay of the BM amplitude past the first peak. For $\beta=0.1$ *DAMP, the secondary peaks of the BM amplitude are observable for frequencies $0.4-2 \mathrm{kHz}$. Moreover, the maximum BM displacement for $2 \mathrm{kHz}$ is more basally compared with data reported by Georg von Bekesy. This indicates that the damping coefficient of $\beta=0.1 *$ DAMP is too small. For $\beta=$ DAMP, the secondary peaks are significantly reduced and for $\beta=10 * \mathrm{DAM}$ almost not observable. Increase in the $\mathrm{BM}$ prosthesis. The specimens were stimulated with a sound pressure level of $90 \mathrm{~dB}$ SPL at the tympanic membrane

damping also shifts the maximum BM displacement toward the apex. The simulation results have also shown that the change in the damping coefficient $\beta$ affects only on the BM motion and the RW motion remains the same. Therefore, we claim that the BM damping coefficient should be assumed as DAMP or greater.

\subsection{FE simulation of RW membrane vibration following stapedotomy surgery}

After validation, the FE model was used to investigate the effect of piston prosthesis implantation on the RW vibration. 


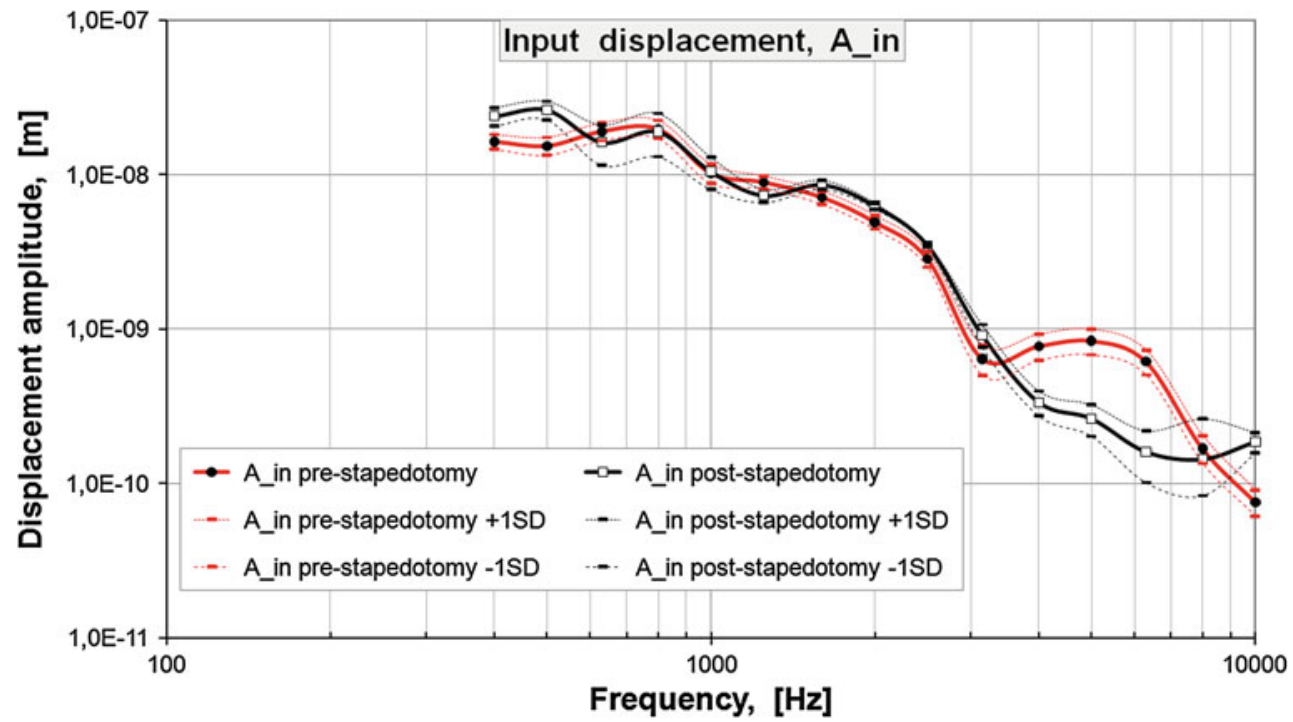

Fig. 4 Pre-stapedotomy and post-stapedotomy experimental input displacement amplitude (A_in) frequency profiles assumed as the amplitudes of the harmonic displacement excitations in the pre-stapedotomy and post-stapedotomy FE models. The figure presents the average values of displacement amplitude for specimen 1 (A_in, thick, solid curve line) with standard deviation \pm 1 SD markers jointed by a thin, dashed curve line. The average and the standard deviation were calculated for each measurement frequency based on the 73 pre-stapedotomy and the 38 post-stapedotomy amplitude frequency profiles showed in Kwacz et al. (2012, Fig. 2)

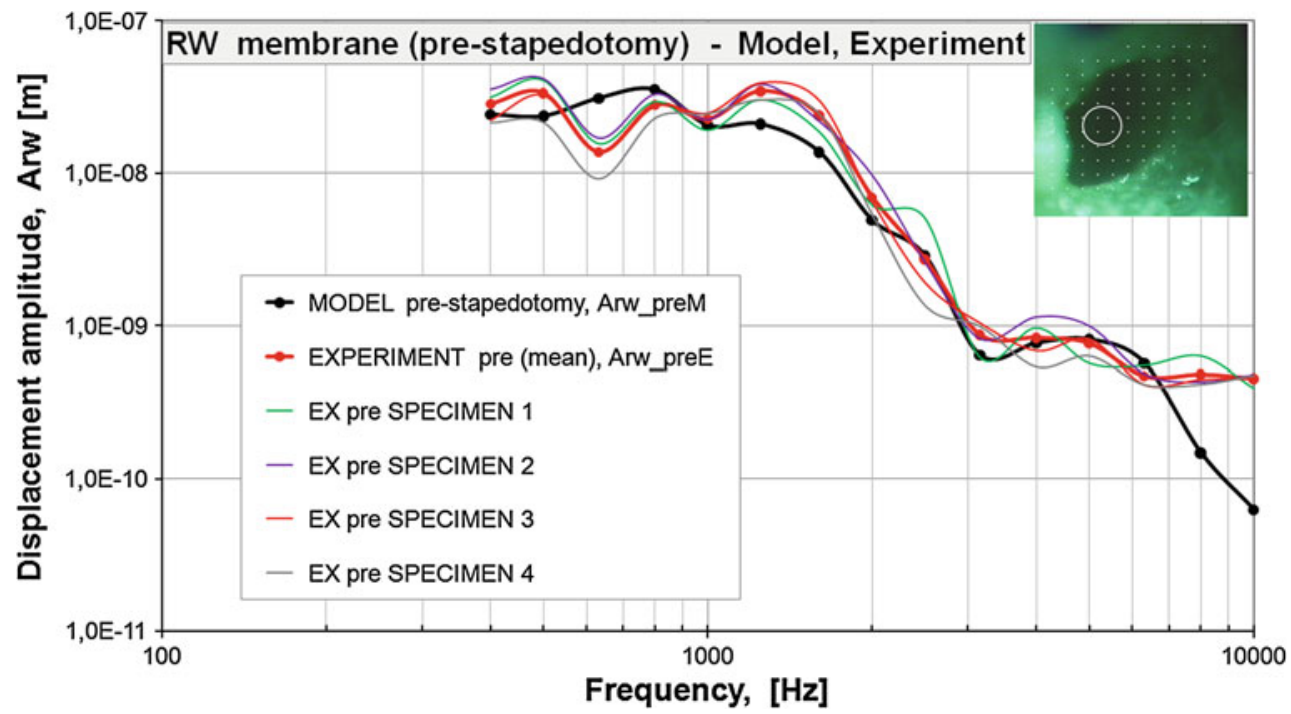

Fig. 5 Pre-stapedotomy amplitude frequency profiles of the RW membrane displacement. The figure presents the model-derived frequency response curve (MODEL pre-stapedotomy, thick, black, solid curve line) while the amplitudes of the harmonic displacement excitations are given in Table 2 (A_in pre-stapedotomy) in comparison with the corre- sponding curves (EX pre SPECIMEN, thin, colored, solid curve lines) obtained from four temporal bone specimens in the pre-stapedotomy state when $90 \mathrm{~dB}$ SPL pure tones were applied in the external ear canal and values of the average displacement amplitude of four points for all specimens (EXPERIMENT pre(mean), thick, gray, dashed curve line)
Firstly, a piston prosthesis with a diameter of $0.4 \mathrm{~mm}$ was considered. Figure $7 \mathrm{a}$ shows the frequency response curves of the RW membrane displacement derived from the FE post-stapedotomy model (Arw_postM0.4) and control experimental curves measured from the human temporal bones following the stapedotomy surgery (Arw_postE0.4) compared to the curve for the FE pre-stapedotomy model.
As can be seen, the FE model shows a maximum reduction in RW membrane displacement amplitude for the poststapedotomy state within the $4-8 \mathrm{kHz}$ frequency range. The post-stapedotomy FE model displacement amplitude curve (Arw_postM0.4) falls well within the range of the four temporal bone control experimental curves for frequencies above $1.25 \mathrm{kHz}$. Compared with the control experimental curves, 
Table 2 Amplitude of the harmonic displacement excitations in the pre-stapedotomy and post-stapedotomy FE models for 15 subsequent frequencies

\begin{tabular}{llllll}
\hline $\begin{array}{l}\text { Measurement } \\
\text { frequency, } f \\
(\mathrm{kHz})\end{array}$ & $\begin{array}{l}\text { A_in pre- } \\
\text { stapedotomy }(\mathrm{m})\end{array}$ & $\begin{array}{l}\text { A_in post- } \\
\text { stapedotomy }(\mathrm{m})\end{array}$ & $\begin{array}{l}\text { Measurement } \\
\text { frequency, } f \\
(\mathrm{kHz})\end{array}$ & $\begin{array}{l}\text { A_in pre- } \\
\text { stapedotomy (m) }\end{array}$ & $\begin{array}{l}\text { A_in post- } \\
\text { stapedotomy }(\mathrm{m})\end{array}$ \\
\hline 0.40 & $1.64 \cdot 10^{-8}$ & $2.93 \cdot 10^{-8}$ & 2.50 & $2.84 \cdot 10^{-9}$ & $3.48 \cdot 10^{-9}$ \\
0.50 & $1.53 \cdot 10^{-8}$ & $2.62 \cdot 10^{-8}$ & 3.15 & $6.40 \cdot 10^{-10}$ & $9.10 \cdot 10^{-10}$ \\
0.63 & $1.90 \cdot 10^{-8}$ & $1.62 \cdot 10^{-8}$ & 4.00 & $7.73 \cdot 10^{-10}$ & $3.35 \cdot 10^{-10}$ \\
0.80 & $1.97 \cdot 10^{-8}$ & $1.89 \cdot 10^{-8}$ & 5.00 & $8.36 \cdot 10^{-10}$ & $2.62 \cdot 10^{-10}$ \\
1.00 & $1.02 \cdot 10^{-8}$ & $1.05 \cdot 10^{-8}$ & 6.30 & $6.14 \cdot 10^{-10}$ & $1.59 \cdot 10^{-10}$ \\
1.25 & $8.92 \cdot 10^{-9}$ & $7.31 \cdot 10^{-9}$ & 8.00 & $1.69 \cdot 10^{-10}$ & $1.43 \cdot 10^{-10}$ \\
1.60 & $7.12 \cdot 10^{-9}$ & $8.58 \cdot 10^{-9}$ & 10.00 & $7.57 \cdot 10^{-11}$ & $1.85 \cdot 10^{-10}$ \\
2.00 & $4.93 \cdot 10^{-9}$ & $6.25 \cdot 10^{-9}$ & & & \\
\hline
\end{tabular}

the post-stapedotomy FE model showed higher values for the RW membrane displacement amplitudes for frequencies from 0.5 to $1.0 \mathrm{kHz}$. However, in general, the simulation from the post-stapedotomy FE model shows a pattern similar to the mean experimental curve.

Figure $7 \mathrm{~b}$ shows the $0.4-$ and $0.6-\mathrm{mm}$ piston-induced changes in the RW membrane displacement amplitude ( $\triangle$ Arw, where the magnitude of $\Delta$ Arw equals $20 * \log _{10}$ $\left.\left[\mathrm{Arw}_{\text {post }} / \mathrm{Arw}_{\text {pre }}\right]\right)$. The model-derived magnitudes of $\Delta \mathrm{Arw}$ across the pre-stapedotomy and the $0.4-\mathrm{mm}$ piston poststapedotomy state were 8.8, 9.1, 14.4, 10.5, 18.6, 20.8, 21.0, and $22.5 \mathrm{~dB}$ at frequencies of $0.5,0.8,1.6,3.15,4.0,5.0$, 6.3 , and $8 \mathrm{kHz}$, respectively. The mid- and high-frequency decrease in the magnitude of Arw has similar features to the mid- and high-frequency hearing loss observed in patients undergoing stapedotomy.

After simulation for the $0.4-\mathrm{mm}$ piston prosthesis, the frequency response curves of the RW membrane displacement were derived from the FE post-stapedotomy model for the 0.6-mm piston prosthesis and the new stapes prosthesis currently under investigation at Warsaw University of Technology. Figure 8 presents the model-derived frequency response curves for the post-stapedotomy state using the 0.4- and 0.6$\mathrm{mm}$ piston stapes prosthesis compared to the curve for the FE pre-stapedotomy state (normal ear). The model-derived displacement amplitude difference across the curves for 0.4 and $0.6-\mathrm{mm}$ piston prosthesis was approximately $4 \mathrm{~dB}$ at all frequencies. However, both post-stapedotomy model-derived frequency response curves were still below the curve for the normal ear.

\section{Discussion}

At present, the piston stapes prosthesis is the most commonly used prosthesis replacing an immobilized stapes in cases of otosclerosis. However, the majority of patients report a lack of satisfactory hearing outcomes following the stapes surgery, especially for frequencies above $2 \mathrm{kHz}$. This leads to an in-depth analysis of the process of sound conduction through the inner ear structures and to an attempt to develop a new type of stapes prosthesis providing a sufficient level of excitation to the vibrations of perilymphatic fluid.

The results of our modeling and experimental studies showed the differences in the RW vibrations between physiological conditions and following stapedotomy. The motion of the RW membrane has been used to determine the efficiency of the transfer of acoustic energy to the inner ear and to predict hearing results following some types of middle ear reconstructions (Asai et al. 1999; Mehta et al. 2003; Stenfelt et al. 2004b; Chien et al. 2007). This justifies the experimental and modeling investigations of the RW vibration in the case of stapedotomy surgery. To develop an appropriate simulation model of cochlear macromechanics, knowledge of the vibration parameters has been required, based on the experimental measurements. We used the LDV technique to find the displacement amplitude of the SF, the piston of the stapes prosthesis, and the RW membrane from fresh cadaver temporal bone specimens. We do not publish the phase data because our data differ substantially from the earlier studies (e.g., Stenfelt et al. 2004a). We suspect that the experimental phase data obtained by us are not correlated in time with the sound signal supplied to the external ear canal. Therefore, the analysis of the phase data without repeating the measurements is impossible. Nevertheless, our measurement results of the displacement amplitudes were comparable with other researchers' studies (Asai et al. 1999; Huber et al. 2003, 2006; Stenfelt et al. 2004a,b). Figure 9 compares our measurement results of the stapes displacement amplitude to Fig. 5 of Asai et al. (1999), Fig. 6C of Huber et al. (2003), Fig. 2 of Huber et al. (2006), and Fig. 4a of Stenfelt et al. (2004a). Stenfelt et al. (2004a) reported the velocity amplitude of points on the stapes footplate. We recalculated these data to obtain the displacement amplitude (Asf) according to the formula 

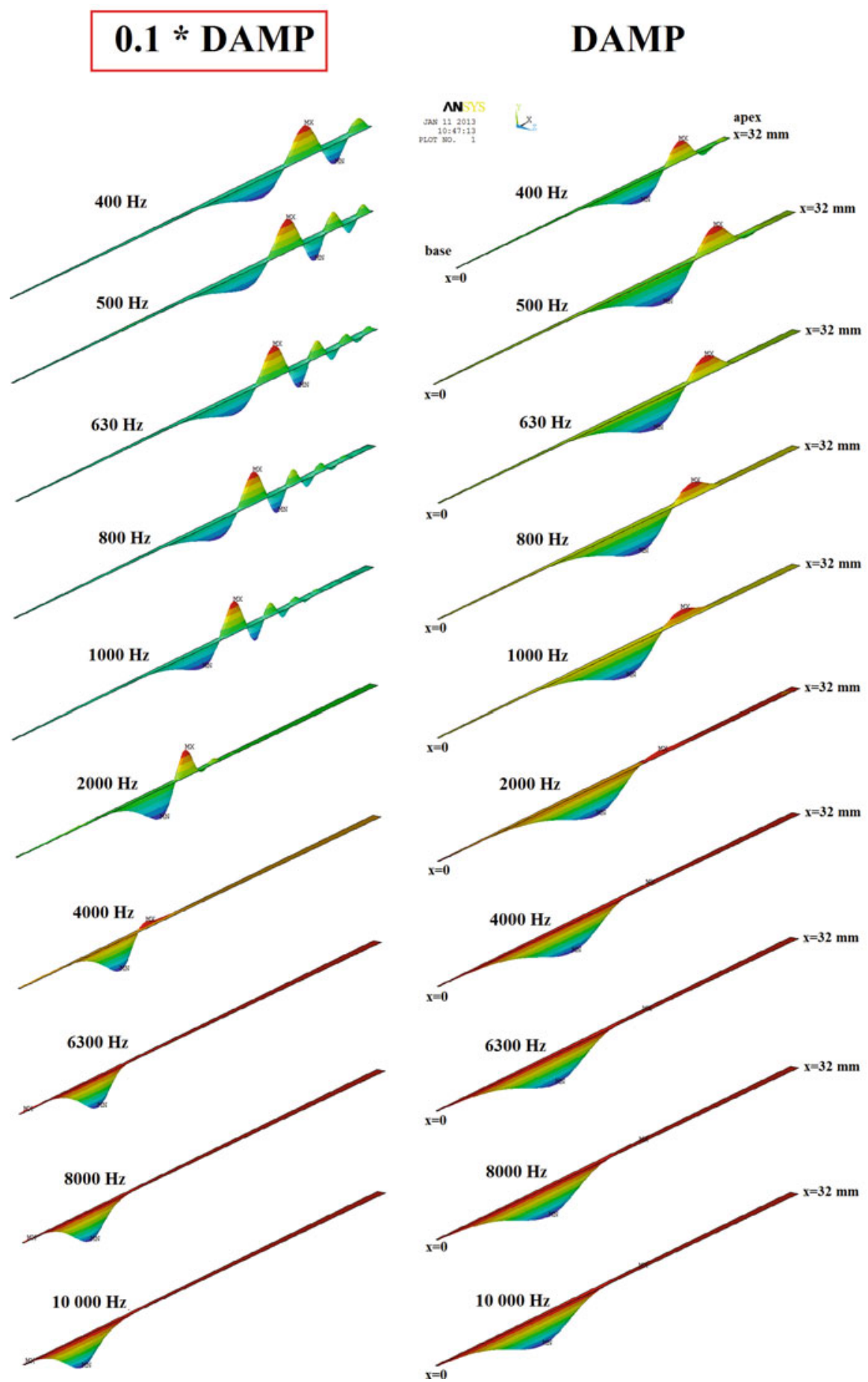

\section{$10 *$ DAMP}
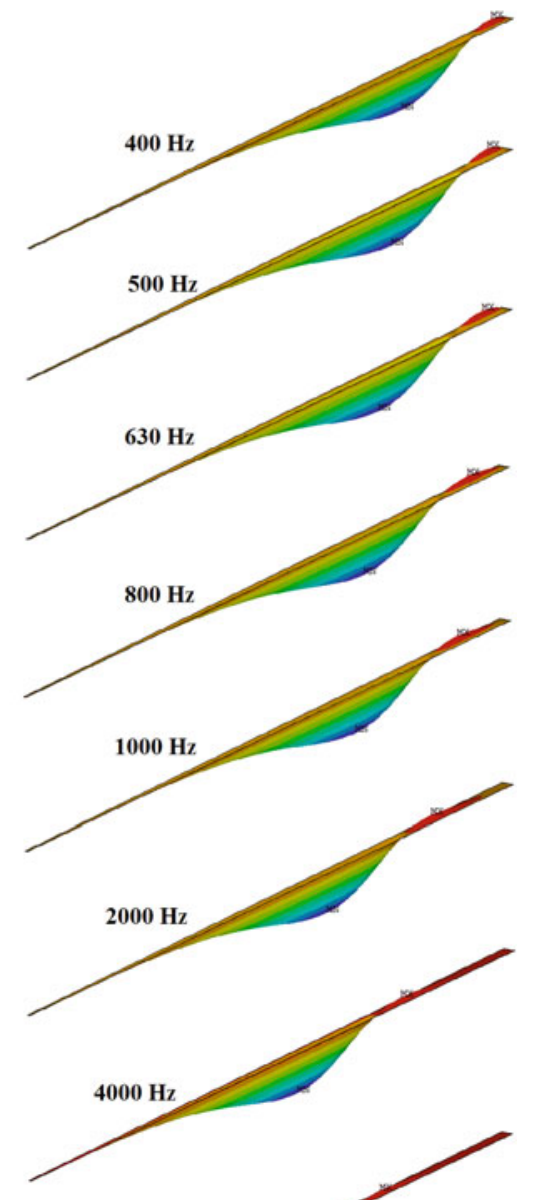

Fig. 6 The traveling wave pattern along the BM from the base $(x=0)$ to the apex $(x=32 \mathrm{~mm})$ at frequencies of $0.4-10 \mathrm{kHz}$ for different values of the BM damping coefficient $\beta$ (0.1*DAMP, DAMP, $10 *$ DAMP, where DAMP changes linearly from $0.2 \mathrm{E}-03 \mathrm{~s}$ at the base to $0.1 \mathrm{E}-02 \mathrm{~s}$ at the apex)

Asf $=\mathrm{Vsf} / \cos (2 * 3.14 * f)$ where Vsf-velocity amplitude, $f$-frequency. Asai et al. (1999), Huber et al. (2003, 2006), and Stenfelt et al. (2004a) performed the experiments when a sound stimulation of $80 \mathrm{~dB}$ SPL was presented at the tympanic membrane. Because we measured the stapes displace- ment at $90 \mathrm{~dB}$ SPL, our measurement results are slightly higher compared to others. Figure 10 shows comparison of the RW displacement amplitude for the pre-stapedotomy state between (Asai et al. 1999, Fig. 5, center of the RW), Stenfelt et al. (2004a, Fig. 4c, the highest curve), Stenfelt 

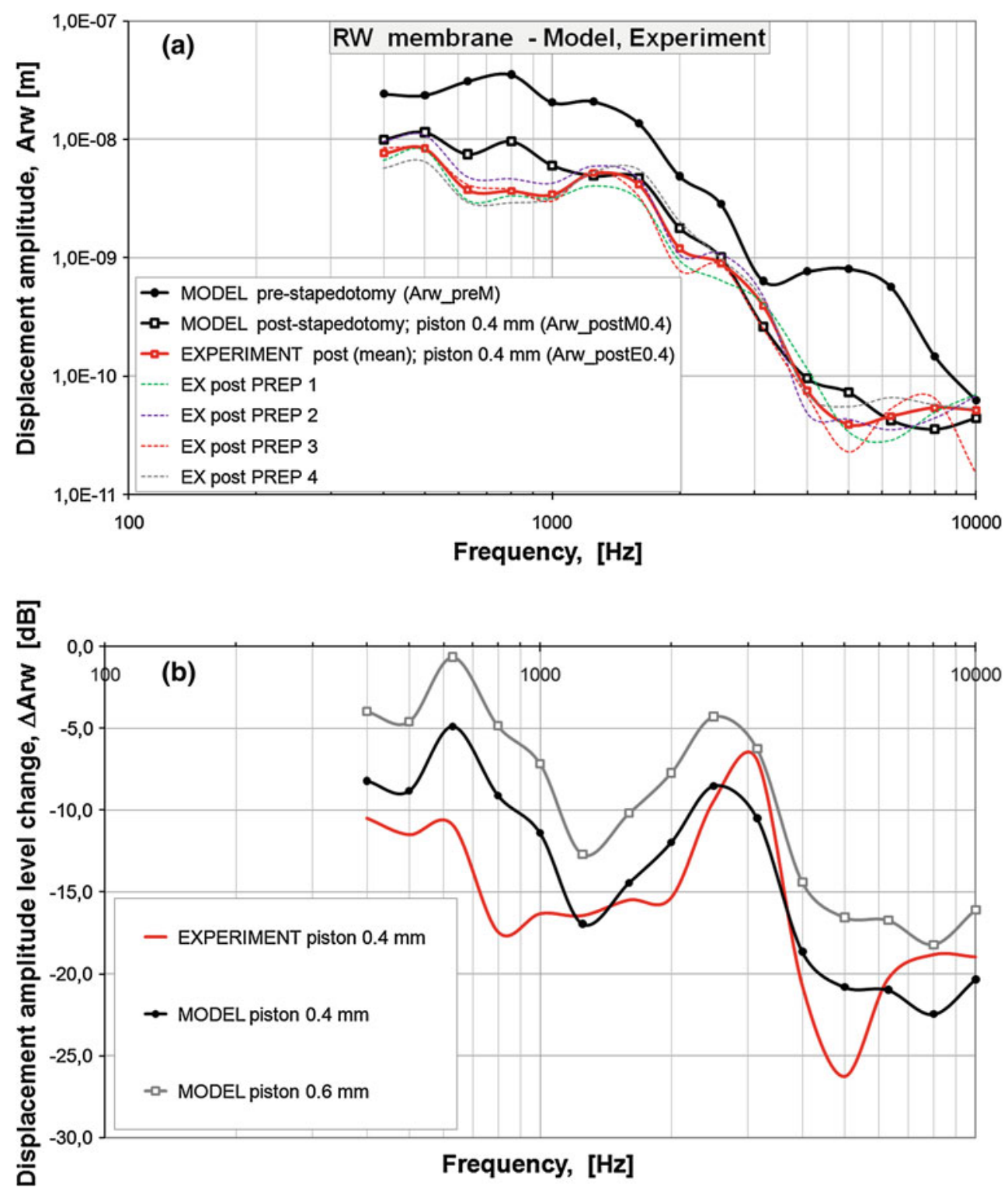

Fig. 7 a Post-stapedotomy amplitude frequency profiles of the RW membrane displacement (Arw) while the $0.4-\mathrm{mm}$ piston stapes prosthesis was inserted into the oval window. The figure presents the modelderived frequency response curve (MODEL post-stapedotomy, thick, black, solid curve line, white squares) while the amplitudes of the harmonic displacement excitations are given in Table 2 (A_in poststapedotomy) in comparison with the corresponding curves (EX post SPECIMEN, thin, colored, dashed curve lines) obtained from four temporal bone specimens in the post-stapedotomy state when $90 \mathrm{~dB}$ SPL pure tones were applied in the external ear canal, and the values of average displacement amplitude of four points for all specimens (EXPERIMENT post(mean), thick, red, solid curve line). The

et al. (2004b, Fig. 3a, the highest curve), and the present study. All curves are similar, but it should be noted that our measurement was made with $90 \mathrm{~dB}$ SPL. However, because complicated vibration patterns of the RW, comparing the RW membrane vibration at a single point, can give model-derived pre-stapedotomy amplitude frequency profile of the RW membrane displacement (MODEL pre-stapedotomy, thick, black, solid curve line, black circles) was shown to compare with the poststapedotomy profiles. b Changes in the model-derived RW membrane displacement amplitude ( $\Delta$ Arw, where the magnitude of $\Delta$ Arw equals $\left.20 * \log _{10}\left[\mathrm{Arw}_{\text {post }} / \mathrm{Arw}_{\mathrm{pre}}\right]\right)$ induced by the $0.4-\mathrm{mm}$ piston stapes prosthesis (MODEL piston $0.4 \mathrm{~mm}$, black, solid curve line), the $0.6-\mathrm{mm}$ piston stapes prosthesis (MODEL piston $0.6 \mathrm{~mm}$, gray, solid curve line) and measured before and after experimental stapedotomy with the 0.4-mm piston prosthesis (EXPERIMENT piston $0.4 \mathrm{~mm}$, red, solid curve line). For the model curves, the amplitudes of the harmonic displacement excitations are given in Table 2

erroneous results. To our knowledge, only Stenfelt et al. (2004b) measured the RW vibration for the post-stapedotomy state. Stenfelt et al. made their measurement for a $0.6-\mathrm{mm}$ piston stapes prosthesis with a sound pressure level at the tympanic membrane of $80 \mathrm{~dB}$ SPL. The results from nine 


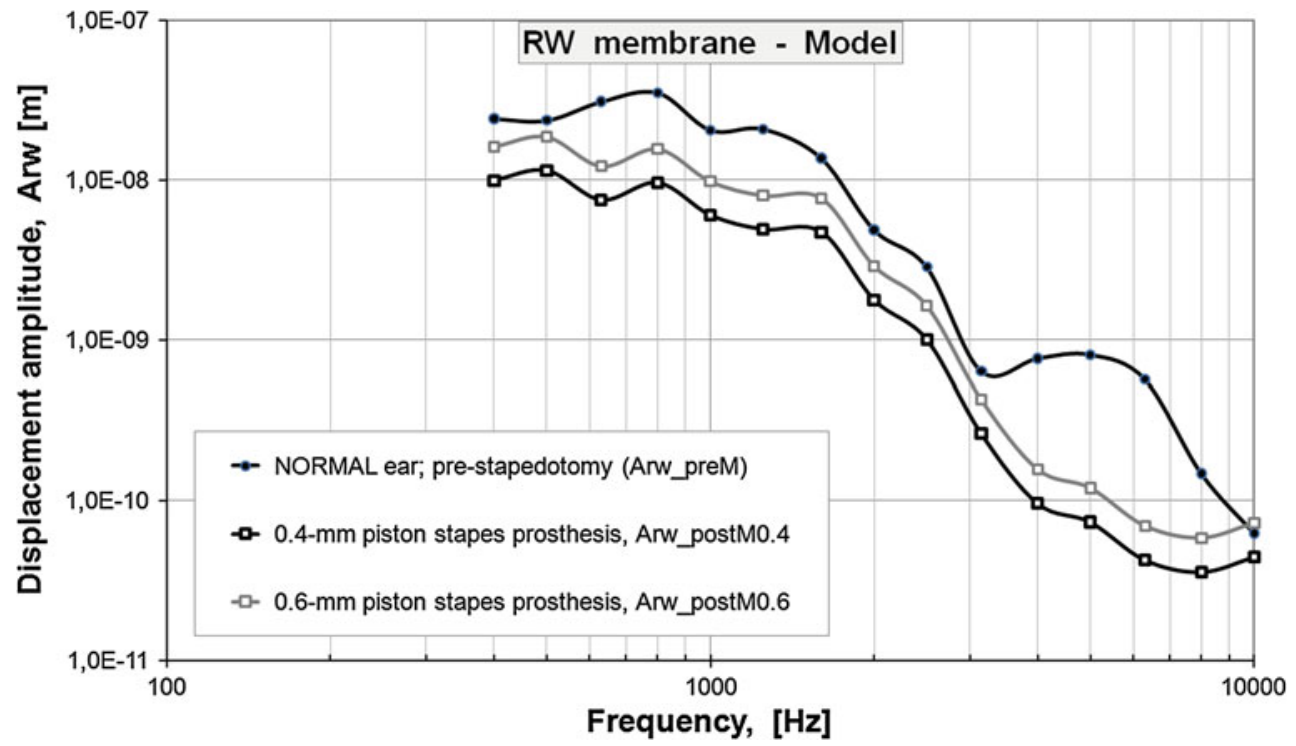

Fig. 8 Pre-stapedotomy and post-stapedotomy model-derived amplitude frequency profiles of the RW membrane displacement (Arw). The figure presents the pre-stapedotomy frequency response curve (Arw_preM, NORMAL ear, thick, black, solid curve line, black circles) while the amplitudes of the harmonic displacement excitations are given in Table 2 (A_in pre-stapedotomy) in comparison with the post-stapedotomy curves while the $0.4-\mathrm{mm}$ piston stapes prosthesis
(Arw_postM0.4, 0.4-mm, thick, black, solid curve line, white squares) and 0.6-mm piston stapes prosthesis (Arw_postM0.6, 0.6-mm, thick, gray, solid curve line) were inserted into the oval window. The modelderived post-stapedotomy amplitude frequency profile of the RW membrane displacement was obtained for the amplitudes of the harmonic displacement excitations given in Table 2 (A_in post-stapedotomy)

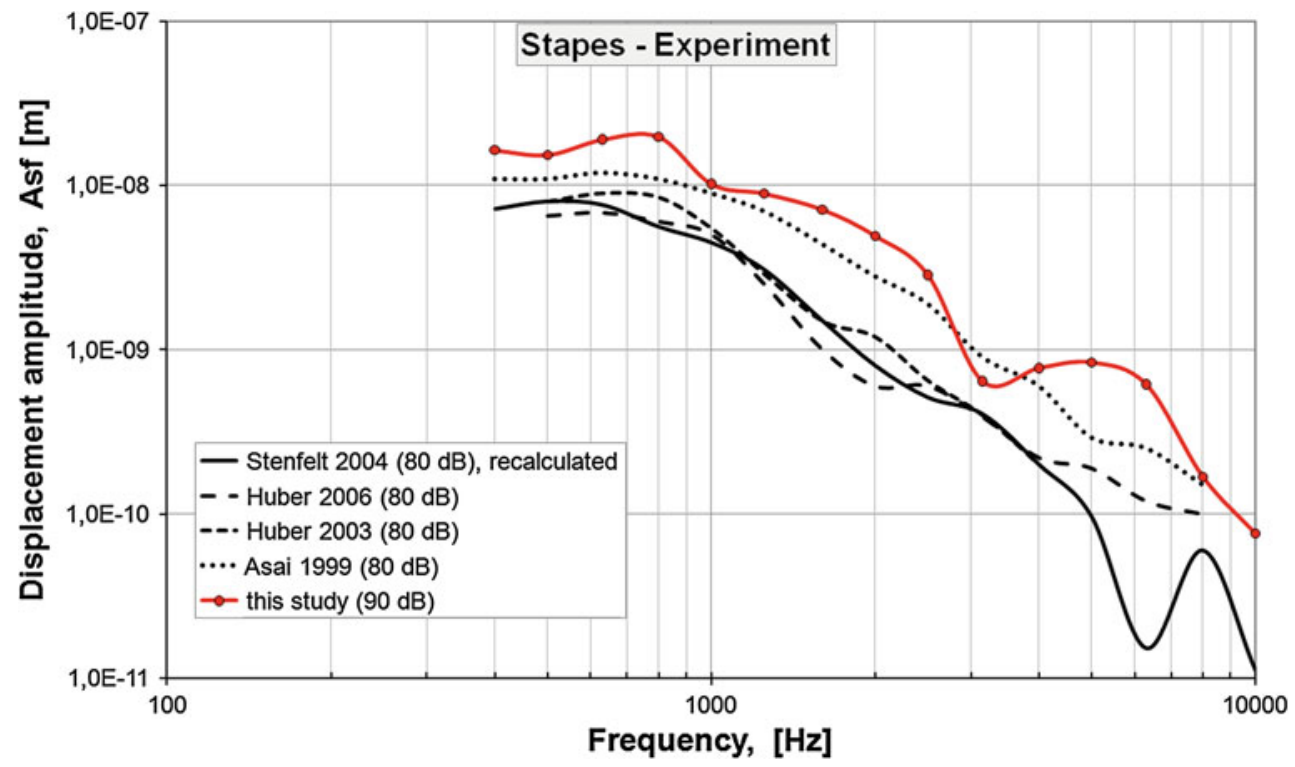

Fig. 9 Comparison of stapes displacement amplitudes between Asai et al. (1999, $80 \mathrm{~dB}$ SPL at the TM), Huber et al. (2003 and 2006, $80 \mathrm{~dB}$ SPL at the TM), Stenfelt et al. (2004a, $80 \mathrm{~dB}$ SPL at the TM), and the present study ( $90 \mathrm{~dB}$ SPL at the TM). The velocity amplitudes reported by

target positions closed to the center of the RW membrane were presented as relative measures (Fig. 6, Stenfelt et al. 2004b). Therefore, it is difficult to compare our measurement results of the RW displacement amplitude (Arw) for a $0.4-\mathrm{mm}$ piston stapes prosthesis and $90 \mathrm{~dB}$ SPL to the
Stenfelt et al. (2004a) were recalculated to obtain the displacement amplitudes according to the formula $\mathrm{A}_{\text {displacement }}=$ $\mathrm{A}_{\text {velocity }} / \cos (2 * 3.14 * f)$ where $\mathrm{A}_{\text {velocity }}$-velocity amplitude, $f$ frequency

measurement results reported by Stenfelt et al. (2004b). In our measurement, the piston prosthesis substantially changed the vibration pattern of the RW membrane for the entire frequency range $0.5-10 \mathrm{kHz}$ (Wysocki et al. 2011). Similar results were recorded by Stenfelt et al. (2004b). This suggests 


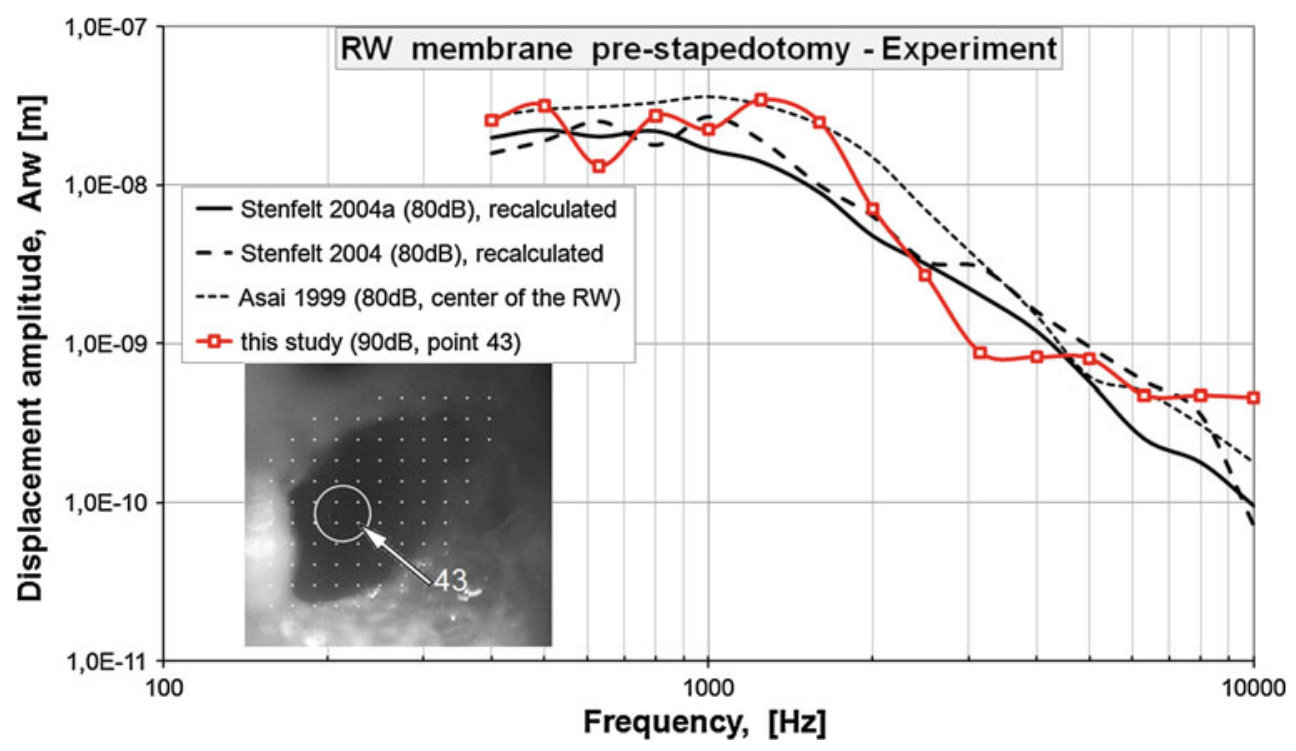

Fig. 10 Comparison of round window displacement amplitudes for the pre-stapedotomy state between Asai et al. (1999, Fig. 5, center of the RW, $80 \mathrm{~dB}$ SPL at the TM), Stenfelt et al. (2004a, Fig. 4c, the highest curve, $80 \mathrm{~dB}$ SPL at the TM), Stenfelt et al. (2004b, Fig. 3a, the highest curve, $80 \mathrm{~dB}$ SPL at the TM), and the present study (scan

that the fluid volume displacement at the RW should be calculated to estimate the stimulation of the cochlea, especially in the case of stapedotomy surgery.

As has been demonstrated in the literature, the fresh temporal bone preparation is a good model for preclinical, in vitro studies, and laser Doppler vibrometry is a suitable tool for assessing middle ear prosthesis performance. Passive macromechanics of the hearing organ in fresh cadaver temporal bones functions similarly to physiological conditions provided that the temporal bone specimens are harvested from human cadavers within $48 \mathrm{~h}$ of death, protected from drying and stored without freezing until measurement, and the measurements are taken within 1-6 days of death (Aibara et al. 2001; Rosowski et al. 1990; Goode et al. 1993).

Our temporal bone preparation enabled us to make control measurements of the round window membrane vibration before and after experimental stapedotomy. We used the RW membrane displacement amplitudes (Arw) as an index of sound delivery to the cochlear partition. This assumption is similar to those made by Kringlebotn and Gundersen (1985), Kringlebotn (1995), Asai et al. (1999), Mehta et al. (2003), Stenfelt et al. (2004a,b), Chien et al. (2007). The differences between Arw for the pre-stapedotomy and post-stapedotomy states can be treated as an incomplete closure of the air-bone gap resulting in conductive hearing loss in patients undergoing stapedotomy.

The stapedotomies that we performed in our temporal bones were all relatively similar in piston diameters $(0.4$ and $0.6 \mathrm{~mm}$ ) and were at similar locations (piston in the center point 43 on the RW membrane, $90 \mathrm{~dB}$ SPL at the TM). The velocity amplitudes reported by Stenfelt et al. (2004a, 2004b) were recalculated to obtain the displacement amplitudes according to the formula $\mathrm{A}_{\text {displacement }}=\mathrm{A}_{\text {velocity }} / \cos (2 * 3.14 * f)$ where $\mathrm{A}_{\text {velocity }}$-velocity amplitude, $f$-frequency

of the SF, ribbon around the long process of the incus) to the clinical procedures. It would be possible in future studies to use the temporal bone preparations to systematically examine varying dimensions of the new stapes prosthesis in an attempt to determine whether these dimensions affect the resulting hearing outcomes.

In all four bones, the Arw magnitude was decreased in response to piston insertion in the SF, in particular at frequencies exceeding $2 \mathrm{kHz}$ (Fig. 7b). This is consistent with the mid- and high-frequency air-bone gap observed in patients undergoing stapedotomy. The reduction in Arw magnitude by a piston prosthesis is also consistent with the approximately fivefold lower stimulation of perilymph vibration in response to air-conducted stimulus compared to physiological situation (Stenfelt et al. 2004b; Wysocki et al. 2011).

The objective of this study was to assess the influence of stapedotomy surgery on the round window membrane vibration and to estimate the postoperative outcomes using the finite element (FE) method. We have presented a $3 \mathrm{D}$ FE cochlear model to predict the RW membrane vibrations induced by the normal SF, the 0.4-mm piston prosthesis, and the $0.6-\mathrm{mm}$ piston prosthesis. Due to the highly complex geometry of the cochlea in the FE model presented, the cochlear curvature, the Reissner's membrane and the micromechanical structure of the organ of Corti are omitted, and the scala media is included in the SV. We also assumed that the cochlea is detached from the middle ear structures and that stimulation of the perilymph occurs by applying the vibrations to the oval window. These simplifying assumptions 
have been accepted by many authors for investigating the cochlear macromechanics using mathematical, FE, and physical models (Andoh and Wada 2004; Kolston and Ashmore 1996; Lechner 1993; Neely 1981; Steele and Lim 1999; Watts 2000; Wittbrodt et al. 2006; Gan et al. 2007). All of these models assumed that stimulation of the cochlea occurs by applying the vibrations to the oval window or to the one side of the scala vestibule through the SF.

Most of the experiments were performed to investigate the physiological motion of the SF. It has been reported that the physiological motion of the SF in response to acoustic stimulation is predominantly piston-like at low frequencies and includes rocking around the short and long axes of the SF at high frequencies (Heiland et al. 1999; Hato et al. 2003; Sim et al. 2010). Nevertheless, most current human cochlear models do not consider the effects of this rocking motion because it is believed not to contribute to fluid volume displacement at the oval window and to have negligible effects on cochlear macromechanics (Kolston and Ashmore 1996; Lim and Steele 2002; Shera et al. 2005; Pozrikidis 2007, 2008). The same assumption has been made for this study and both the SF and the piston prosthesis motion were assumed as piston-like. In our FE cochlear model, the stimulation of the perilymph was assumed as real measured amplitude vibrations of both the stapes in the physiological state and the stapes piston prosthesis in the post-implantation state. This assumption takes into account the change in the cochlear input impedance resulting from interactions between the cochlea and the normal or implanted middle ear. It was shown experimentally that a small-fenestra stapedotomy acts to decrease the impedance that loads the ossicular chain (Rosowski et al. 2003), because of difference in area between the normal SF and the piston of the stapes prosthesis. Moreover, stapedotomy bypasses the impedance of the $\mathrm{AL}$ which is replaced by an unknown impedance of the seal around the piston (we used a blood clot as in clinical situations). These two factors (the area ratio and bypassing of the AL impedance) together change the impedance imposed by the inner ear on the middle ear such that equal sound pressures levels in the external ear canal produce different vibrations of the prosthesis compared with normal stapes motions. To predict hearing results after stapedotomy surgery using different stapes prostheses, the FE model requires an adjustment of the input displacement amplitudes (A_in post-stapedotomy). This is the main difficulty in this approach.

Another issue is the lack of mechanical properties of the cochlear soft tissues, such as the BM, the RW membrane, and the AL, obtained from experimental measurements. In view of the above, we have initially assumed the values for mechanical parameters given by Gan et al. (2007). These parameters were then checked in the validation process by comparing the RW membrane displacement amplitudes (Arw) derived from the FE model with the experimental data obtained from temporal bone experiments for the prestapedotomy state. A similar approach has been used by many authors (Ferris and Prendergast 2000; Sun et al. 2002; Koike et al. 2002; Gan et al. 2004, 2007). After the validation process, the density of the AL and all mechanical properties of the perilymph fluid, the BM, and the RW membrane were left unchanged (Table 1). For the AL, the Young's modulus of 5.5 MPa proved to be too high, resulting in a large reduction in the RW displacement amplitude, especially for frequencies below $3 \mathrm{kHz}$. The stiffness of the $\mathrm{AL}$ was predicted to reduce the vibration amplitude of the stapes (Kringlebotn 1988; Ferris and Prendergast 2000), thereby reducing the RW vibration amplitude. To minimize the difference between the FE model and experimental data, the Young's modulus for the AL in our FE model was decreased to 0.2 MPa. This value is the same as assumed by Gan et al. (2006). Also, the Raleigh damping parameters $\alpha=0 \mathrm{~s}^{-1}$ and $\beta=0.00005 \mathrm{~s}$ for both the $\mathrm{AL}$ and the $\mathrm{SF}$ were then determined by the validation process. The final values of the mechanical properties used in our FE model are listed in Table 1. The FE model-predicted displacement amplitude of the RW (Arw_preM) for the prestapedotomy state is plotted with black line in Fig. 5, and it can be seen that the results match the experimental data in the frequency range of $0.5-7 \mathrm{kHz}$. At higher frequencies, Arw_preM lies below the experimental curves, likely due to the complex high-frequency three-dimensional motion of the stapes (Heiland et al. 1999; Hato et al. 2003). Our FE model assumes the values of input displacement amplitudes (A_in) in the pre-stapedotomy state (Fig. 4, red line), which may be different from the normal physiological state. The A_in pre-stapedotomy amplitudes were applied to all stapes footplate nodes in the direction perpendicular to the footplate. The rocking motion of the stapes was neglected. The values of A_in amplitudes were taken as equal to the displacement amplitudes measured on the stapes head. This assumption is completely correct only below $2 \mathrm{kHz}$. Above $2 \mathrm{kHz}$, a rocking motion increases logarithmically with frequency (Heiland et al. 1999). In this frequency range, measurement of stapes head may represent vibration only at the center of the footplate. For frequencies above $7 \mathrm{kHz}$, the fluctuations of the rocking ratio (Heiland et al. 1999), defined as the maximum difference in displacement between the anterior and posterior footplate to displacement at the center of the stapes footplate, correspond to the fluctuations of the pressure in both the scala vestibuli and scala tympani reported by Nakajima et al. (2008; Fig. 3). This suggest that in this frequency range, complex footplate motion may induce higher volume velocity compared to piston footplate motion with velocity measured at the center of the footplate. The scala tympani pressure and volume velocity at the RW have a significant effect on the vibration amplitudes of the RW membrane. This may explain the discrepancy of the FE model results and experiments in our Fig. 5 for the pre-stapedotomy state. 
In the post-stapedotomy state with the 0.4 -mm piston prosthesis, the RW membrane displacement amplitudes derived from our FE cochlear model (Arw_postM0.4) were compared with the data measured from the cadaver temporal bones (Arw_postE0.4) (Fig. 7a). The FE model predicted that the piston stapes prosthesis implantation would affect the RW membrane displacements, which is consistent with the experimental data reported by Wysocki et al. (2011) and Stenfelt et al. (2004b). This leads to the conclusion that the simulation results derived from our 3D FE model are reliable. The value of displacement reduction was related to the piston diameter, and the maximum reduction was achieved at the highest frequencies, such as those exceeding $3 \mathrm{kHz}$ in this study. The reduction in displacement amplitude increases with the increase in frequency and can be treated as an incomplete closure of the preoperative airbone gap resulting in conductive hearing loss following stapedotomy.

To further investigate the effects of our new stapes prosthesis on sound transmission through the inner ear, we conducted a preliminary simulation of the RW frequency-displacement curve. The encouraging simulation results showed that the new stapes prosthesis should be subjected to further detailed investigations, both theoretical and experimental. The study reported here is considered as a step toward the potential engineering applications of the FE model in optimizing new stapes prosthesis.

\section{Conclusion}

The vibration amplitudes of the RW membrane before and after stapes prosthesis implantation can be used to predict the effect of stapedotomy on sound transmission through the inner ear. This study indicates that stapedotomy surgery can be well simulated using the FE cochlear model to predict the hearing results obtained by various types of stapes prostheses. The FE model is suitable for studying the dynamic behaviors of the normal and post-stapedotomy inner ear and potentially useful for designing and testing new stapes prosthesis. Some of our future investigations will focus on identifying such geometric parameters of the new stapes prosthesis which will ensure a near-to-normal hearing restoration, especially after stapedotomy surgery.

Acknowledgments This work was supported by the Polish Ministry of Science and Higher Education (Research Project No. N N518 377637). The authors would like to thank all the reviewers for their valuable comments and suggestions to improve the quality of the paper.

Conflict of interest The authors have no conflicts of interest to declare.

Open Access This article is distributed under the terms of the Creative Commons Attribution License which permits any use, distribution, and reproduction in any medium, provided the original author(s) and the source are credited.

\section{References}

Aibara R, Welsh JT, Puria S, Goode RL (2001) Human middle—ear sound transfer function and cochlear impedance. Hear Res 152(12):100-109

Andoh M, Wada H (2004) Prediction of the characteristics of two types of pressure waves in the cochlea: theoretical considerations. J Acoust Soc Am 116(6):417-425

Asai M, Huber A, Goode R (1999) Analysis of the best site on the stapes footplate for ossicular chain reconstruction. Acta Otolaryngol (Stockh) 119(5):356-361

Böhnke F, Arnold W (1999) 3D-finite element model of the human cochlea including fluid-structure couplings. ORL J Otorhinolaryngol Relat Spec 61(5):305-310

Böhnke F, Arnold W (2007) Finite element model of the stapes-inner ear interface. Adv Otorhino-laryngol 65:150-154

Brownell WE, Bader CR, Bertrand D, de Ribaupierre Y (1985) Evoced mechanical responses of isolated cochlear outer hair cells. Science 227:132-146

Chien W, Ravicz ME, Rosowski JJ, Merchant SN (2007) Measurements of human middle- and inner-era mechanics with dehiscence of the superior semicircular canal. Otol Neurotol 28(2):250-257

Daniel SJ, Funnell WR, Zeitouni AG, Schloss MD, Rappaport J (2001) Clinical applications of a finite-element model of the human middle ear. J Otolaryngol 30(6):340-346

de Boer E (1982) Solving cochlear mechanics problems with higher order differential equations. J Acoust Soc Am 72:1427-1434

Dubreuil C, Bouchayer M, Boulud B, Di Brango P, Reiss T (1994) Otosclerosis: stapedectomy or stapedotomy - a long-term comparative study. Apropos of 1279 cases. Ann Otolaryngol Chir Cervicofac 111(5):249-264 (French)

Emadi G, Richter CP, Dallos P (2004) Stiffness of the Gerbil Basilar membrane: radial and longitudinal variations. J Neurophysiol 91(1):474-488

Feng B, Gan RZ (2004) Lumped parametric model of human ear for sound transmission. Biomechan Model Mechanobiol 3(1):33-47

Ferris P, Prendergast PJ (2000) Middle-ear dynamics before and after ossicular replacement. J Biomech 33(5):581-590

Fukazawa T (2002) How can the cochlea amplifier be realized by the outer hair cells which have nothing to push against? Hear Res 172(1):53-61

Funnell WRJ, Laszlo CA (1978) Modelling of the cat eardrum as a thin shell using the finite-element method. J Acoust Soc Am 63(5):14611467

Funnell WRJ (1996) Low-frequency coupling between eardrum and manubrium in a finite-element model. J Acoust Soc Am 99(5):30363043

Gan RZ, Cheng T, Dai C, Yang F (2009) Finite element modeling of sound transmission with perforations of tympanic membrane. J Acoust Soc Am 126(1):243-253

Gan RZ, Dai C, Wang X, Nakmali D, Wood MW (2010) A totally implantable hearing system-design and function characterization in 3D computational model and temporal bones. Hear Res 263(1-2): 138-144

Gan RZ, Feng B, Sun Q (2004) Three-dimensional finite element modeling of human ear for sound transmission. Ann Biomed Eng 32(6):847-857

Gan RZ, Reeves BP, Wang X (2007) Modeling of sound transmission from ear canal to cochlea. Ann Biomed Eng 35(12):2180-2195 
Gan RZ, Sun Q, Dyer RK Jr, Chang KH, Dormer KJ (2002) Threedimensional modeling of middle ear biomechanics and its applications. Otol Neurotol 23(3):271-280

Gan RZ, Sun Q, Feng B, Wood MW (2006) Acoustical-structural coupled finite element analysis for sound transmission in human earpressure distributions. Med Eng Phys 28(5):395-404

Gan RZ, Wang X (2007) Multi-field finite element analysis for sound transmission in otitis with effusion. J Acoust Soc Am 122(6):35273538

Geisler CD (1993) A realizable cochlear model using feedback from motile outer hair cells. Hear Res 68:253-262

Geisler CD, Sang C (1995) A cochlear model using feed-forward outerhair-cell forces. Hear Res 86:132-146

Gil-Carcedo E, Perez Lopez B, Vallejo LA, Gil-Carcedo LM, Montoya F (2002) Computerized 3-D model to study biomechanics of the middle ear using the finite element method. Acta Otorrinolaringol Esp 53:527-537 (Spanish)

Goode RL, Ball G, Nishihara S (1993) Measurement of umbo vibration in human subjects-method and possible clinical applications. Am J Otol 14(3):247-251

Goode RL, Kilion M, Nakamura K, Nishihara S (1994) New knowledge about the function of the human middle ear: development of an improved analog model. Am J Otol 15(2):145-154

Hanekom T (2001) Three-dimensional spiraling finite element model of the electrically stimulated cochlea. Ear Hear 22(4):300-15

Hanekom T (2005) Modelling encapsulation tissue around cochlear implant electrodes. Med Biol Eng Comput 43(1):47-55

Hato N, Stenfelt S, Goode RL (2003) Three-dimensional stapes footplate motion in human temporal bones. Audiol Neurootol 8(3): $140-152$

Häusler R (2004) Advances in stapes surgery. In: Jahnke K (ed) Middle ear surgery. Thieme, New York, pp 105-119

Heiland KE, Goode RL, Asai M, Huber AM (1999) A human temporal bone study of stapes footplate movement. Am J Otol 20(1):81-86

Hubbard A (1993) A traveling-wave amplifier of the cochlea. Science 259:68-71

Huber AM, Ball GR, Veraguth D, Dillier N, Bodmer D, Sequeira D (2006) A new implantable middle ear hearing device for mixed hearing loss: a feasibility study in human temporal bones. Otol Neurotol 27:1104-1109

Huber AM, Koike T, Wada H, Nandapalan V, Fisch U (2003) Fixation of the anterior malleolar ligament: diagnosis and consequences for heating results in stapes surgery. Ann Otol Rhinol Laryngol 112(4): $348-355$

Iurato S (1962) Functional implications of the nature and submicroscopic structure of the tectorial and basilar membranes. J Acoust Soc Am 34(8):1386-1395

Kelly DJ, Prendergast PJ (2001) An investigation of the middle-ear biomechanics using finite element modelling. ASME BED 50: 369-370

Kelly DJ, Prendergast PJ, Blayney AW (2003) The effect of prosthesis design on vibration of the reconstructed ossicular chain: a comparative finite element analysis of four prostheses. Otol Neurotol 24(1):11-19

Kiefer J, Böhnke F, Adunka O, Arnold W (2006) Representation of acoustic signals in the human cochlea in presence of a cochlear implant electrode. Hear Res 221(1-2):36-43

Kringlebotn M (1988) Network model for the human middle ear. Scan Audiol 17(2):75-85

Kringlebotn M, Gundersen T (1985) Frequency characteristics of the middle ear. J Acoust Soc Am 77(1):159-164

Kringlebotn M (1995) The quality of volume displacement in the inner ear windows. J Acoust Soc Am 98:192-196

Koike T, Wada H, Kobayashi T (2002) Modeling of the human middle ear using the finite-element method. J Acoust Soc Am 111(3):13061317
Kolston PJ, Ashmore JF (1996) Finite element micromechanical modeling of the cochlea in three dimensions. J Acoust Soc Am 99(1): 455-467

Kolston PJ, Viergever E, de Boer E, Diependaal RJ (1989) Realistic mechanical tuning in a micromechanical cochlear model. J Acoust Soc Am 86(1):133-140

Kwacz M, Mrowka M, Wysocki J (2012) Differences in the perilymph fluid stimulation before and after experimental stapedotomy. Acta Bioeng Biomech 14(2):67-73

Lechner TP (1993) A hydromechanical model of the cochlea with nonlinear feedback using PVF2 bending transducers. Hear Res 66(2):202-212

Lim KM, Steele CR (2002) A three-dimensional nonlinear active cochlear model analyzed by the WKB-numeric method. Hear Res 170:190-205

Liu S, White RD (2008) Orthotropic material properties of the gerbil basilar membrane. J Acoust Soc Am 123(4):2160-2171

Lynch TJ, Nedzelnitsky V, Peake WT (1982) Input impedance of the cochlea in cat. J Acoust Soc Am 72(1):108-130

Lyon RF, Mead CA (1988) An analog electronic cochlea. IEEE Trans Acoust Speech and Signal Process 36(7):1119-1134

Mehta RP, Ravicz ME, Rosowski JJ, Merchant SN (2003) Middle-ear mechanics of type III tympanoplasty (stapes columella): I. Experimental studies. Otol Neurotol 24(2):176-185

Mistrík P, Mullaley C, Mammano F, Ashmore J (2009) Threedimensional current flow in a large-scale model of the cochlea and the mechanism of amplification of sound. J R Soc Interface 6:279-291

Møller A (1961) Network model of the middle ear. J Acoust Soc Am 33(2):168-176

Møller P (2007) Stapedectomy versus stapedotomy. Adv Otorhinolaryngol 65:169-173

Nakajima HH, Dong W, Olson ES, Merchant SN, Ravicz ME, Rosowski JJ (2008) Differential intracochlear sound pressure measurements in normal human temporal bones. J Accous Soc Am 10:23-36

Neely ST (1981) Finite difference solution of a two-dimensional mathematical model of the cochlea. J Acoust Soc Am 69(5):1386-1393

Neely ST (1993) A model of cochlear mechanics with outer hair cell motility. J Acoust Soc Am 94(1):137-146

Parthasarati AA, Grosh K, Nuttall AL (2000) Three-dimensional numerical modeling for global cochlear dynamics. J Acoust Soc Am 107(1):474-485

Pozrikidis C (2007) Hydrodynamics of a vibrating stapes prosthesis in stapedotomy. Eng Anal Bound Elem 31(1):1-9

Pozrikidis C (2008) Boundary-integral modeling of cochlear hydrodynamics. J Fluid Struc 24(3):336-365

Ramamoorthy S, Deo NV, Grosh K (2007) A mechano-electroacoustical model for the cochlea: response to acoustic stimuli. J Acoust Soc Am 121:2758-73

Rizer FM, Lippy WH (1993) Evolution of techniques of stapedectomy from the total stapedectomy to the small fenestra stapedectomy. Otolaryngol Clin N Am 26(3):443-451

Rosowski JJ (1996)Models of external- and middle-ear function. In: Hawkins HL, McMullen TA, Popper AN, Fay RR (eds) Auditory Computation. Springer, New York, pp 15-61

Rosowski JJ, Davis O, Merchant SN, Donahue K, Coltrera M (1990) Cadaver middle ears as models for living ears: comparison of middle ear input immittance. Ann Otol Rhinol Laryngol 99(5):403-412

Rosowski JJ, Merchant SN (1995) Mechanical and acoustic analysis of middle ear reconstruction. Am J Otol 16(4):486-497

Rosowski JJ, Mehta RP, Merchant SN (2003) Diagnostic utility of laserdoppler vibrometry in conductive hearing loss with normal tympanic membrane. Otol Neurotol 24(2):165-175

Shatz LF (2005) Slender body method for slender prolate spheroids and hemispheroids on planes in linearized oscillatory flow. Phys Fluids 17(11):113603-113603-11. 
Shaw EA, Stinson MR (1981) Network concepts and energy flow in the human middle ear. J Acoust Soc Am 69(S1):S43

Shea JJJr (1958) Fenestration of the oval window. Ann Otol Rhinol Laryngol 67(4):932-951

Shea JJ, Sanabria F, Smith GD (1962) Teflon piston operation for otosclerosis. Arch Otolaryngol 76(6):516-521

Shera CA, Tubis A, Talmadge CL (2005) Coherent reflection in a twodimensional cochlea: short-wave versus long-wave scattering in the generation of reflection-source otoacoustic emissions. J Acoust Soc Am 118(1):287-313

Somers T, Vercruysse JP, Zarowski A, Verstreken M, Offeciers E (2006) Stapedotomy with microdrill or carbon dioxide laser: influence on inner ear function. Ann Otol Rhinol Laryngol 115(12):880-885

Steele CR, Taber LA (1979) Comparison of WKB calculations and experimental results for three dimensional cochlear models. J Acoust Soc Am 65:1007-1018

Steele CR, Lim KM (1999) Cochlear model with three-dimensional fluid, inner sulcus and feed-forward mechanism. Audiol Neurootol 4(3-4):197-203

Stenfelt S, Hato N, Goode RL (2004a) Fluid volume displacement at the oval and round windows with air and bone conduction stimulation. J Acoust Soc Am 115(2):797-812

Stenfelt S, Hato N, Goode RL (2004b) Round window membrane motion with air conduction and bone conduction stimulation. Hear Res 198(1-2):10-24

Sim JH, Chatzimichalis M, Lauxmann M, Roosli C, Eiber A, Huber AM (2010) Complex stapes motion in human ears. J Assoc Res Otolaryngol 11(3):329-341

Suesserman MF, Spelman FA (1993) Lumped-parameter model for in vivo cochlear stimulation. IEEE Trans Biomed Eng 40(3):237-45

Sun Q, Gan RZ, Chang KH, Dormer KJ (2002) Computer-integrated finite element modeling of human middle ear. Biomech Model Mechanobiol 1(2):109-122

Vanpoucke FJ, Zarowski AJ, Peeters SA (2004) Identification of the impedance model of an implanted cochlear prosthesis from intracochlear potential measurements. IEEE Trans Biomed Eng 51(12):2174-2183
Vincent R, Sperling NM, Oates J, Jindal M (2006) Surgical findings and long term hearing results in 3050 stapedotomies for primary otosclerosis: a prospective study with the otology-neurotology database. Otol Neurotol 27(8):25-47

Wada H, Metoki T, Kobayashi T (1992) Analysis of dynamic behavior of human middle ear using a finite-element method. J Acoust Soc Am 92(6):3157-3168

Watts L (2000) The mode-coupling Liouvelle-Green approximation for a two-dimensional cochlear model. J Acoust Soc Am 108(5):22662271

Wittbrodt MJ, Steele CR, Puria S (2006) Developing a physical model of the human cochlea using microfabrication methods. Audiol Neurotol 11(2):104-112

Wysocki J, Kwacz M, Mrówka M, Skarżyński H (2011) Comparison of round window membrane mechanics before and after experimental stapedotomy. The Laryngoscope 121(9):1958-1964

Yoon Y, Puria S, Steele CR (2009) A cochlear model using the timeaveraged Lagrangian and the push-pull mechanism in the organ of Corti. J Mech Mater Struct 4(5):997-986

Yoon YJ, Steele CR, Puria S (2011) Feed-forward and feed-backward amplification model from cochlear cytoarchitecture: an interspecies comparison. Biophys J 100(1):1-10

Zhang X, Gan RZ (2011) A comprehensive model of human ear for analysis of implantable hearing devices. IEEE Trans Biomed Eng 58(10):3024-3027

Zhao F, Koike T, Wang J, Sienz H, Meredith R (2009) Finite element analysis of the middle ear transfer functions and related pathologies. Med Eng Phys 31(8):907-916

Zwisłocki J (1962) Analysis of the middle ear function. Part I. Input impedance. J Acoust Soc Am 34(9):1514-1523 